\title{
The impact of Governance in Achieving Excellence Performance - Applied study in a Sample of the Iraqi Private Universities
}

\author{
Khleel Ibraheem Ismaeel \\ Accounting Techniques - Technical College of \\ Management \\ Middle Technical University - Baghdad \\ khhlleell@gmail.com
}

\author{
Sally Ibrahim Ahmed Ali \\ Accounting Techniques - Technical College of \\ Management \\ Middle Technical University - Baghdad \\ sally.ibrahim.ahmed@gmail.com
}

Received 10/6/2019

Accepted 25/8/2019

\begin{abstract}
:
This research is based on the evaluation of institutional performance in the special education environment in Iraqi universities, which has become an important issue in the private education sector in Iraq, especially in the context of a strong competitive environment with the synchronization of the development of private universities under the direction of the Ministry of Higher Education and Scientific Research in Iraq to promote the special education. And thus achieve outstanding performance among the Iraqi private universities, as well as knowledge of the relationship of correlation and influence between governance and its dimensions (economic dimension, social dimension, environmental dimension) and outstanding performance.And the impact between governance and its dimensions (economic dimension, social dimension, environmental dimension) and outstanding performance. The questionnaire method was adopted as a key tool in collecting data and information about the research variables and distributing them to a sample of 50 individuals assigned the scientific and moral responsibility to achieve excellence in the level of performance in three of the private Iraqi universities (University College of Madenat al-Elem,Al-Turath University College and Al Isra College,And then using a number of statistical methods for the purpose of analyzing the data for the responses of the sample of the research and the selection of hypotheses through the assistance of the statistical program (SPSS) and then verify the validity of the hypothesis from which the research and based on the results of the analysis concluded the research with a number of conclusions and recommendations was the most important development of awareness of the Iraqi universities the importance of governance given As it represents laws and systems aimed at achieving quality and excellence in performance by choosing the appropriate methods to achieve effective plans for its objectives.
\end{abstract}

Keywords: Governance, governance dimensions, outstanding performance. 


\section{تأثير الحوكمة في تحقيق الأداء المتميز دراسة تطبيقية في عينة من الجامعات العراقية الأهلية}

\author{
سالي إبراهيم أحمد السامرائي \\ تقنيات المحاسبية - الكلية التقنية الإدارية \\ الجامعة التقنية الوسطى - بغداد \\ sally.ibrahim.ahmed@gmail.com
}

\author{
خليل ابراهيم اسماعيل الزبيدي

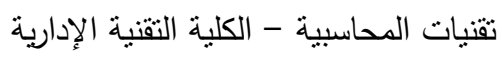 \\ الجامعة التقنية الوسطى - بغداد \\ khhlleell@gmail.com
}

قبول البحث

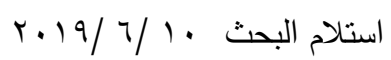

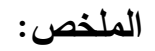

بنطلق البحث إلى تقويم الأداء المؤسساتي في بيئة التعليم الأهلي في الجامعات العراقية والذي أصبح ضرورةً مهمة في قطاع التعليم الأهلي

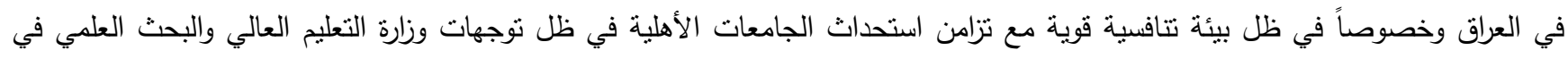

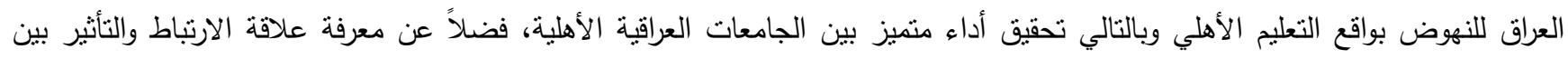

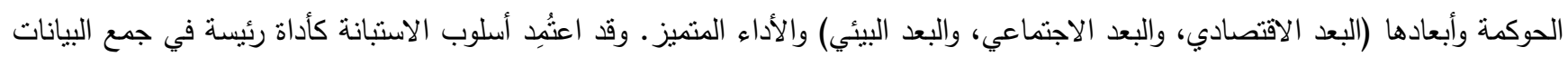

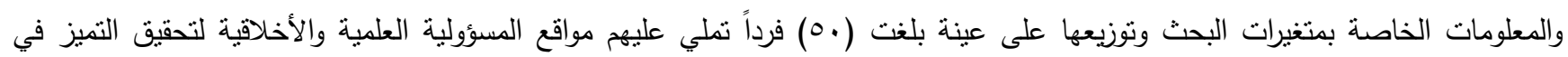

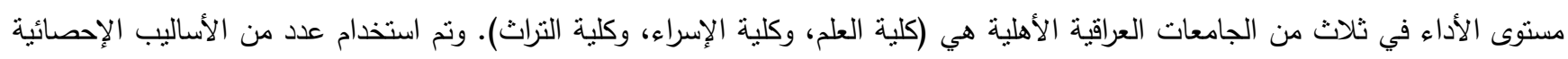

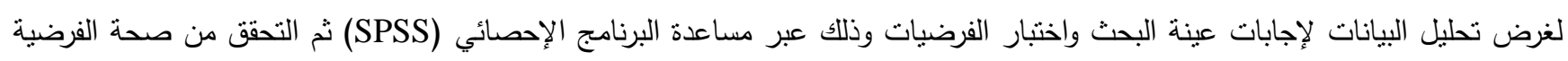

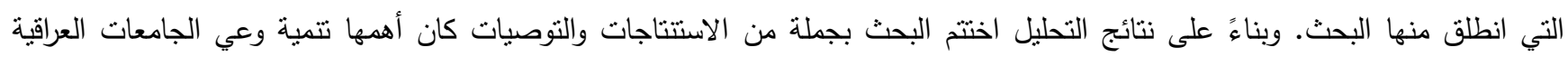

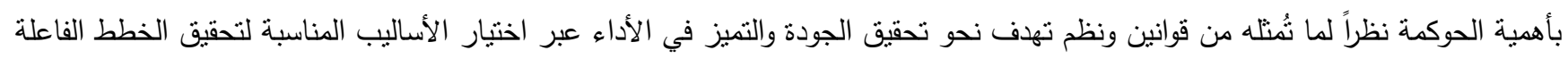

لأهدافها.

الكلمات المفتاحية: الحوكمة، أبعاد الحوكمة، الأداء المتميز.

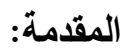

تتسم بالقوة والثفافية وتكون قادرة على رسم استراتيجيات فاعلة مما

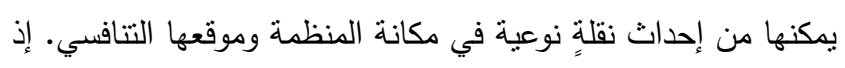
يهدف البحث نحو إبراز تأثثر الحوكمة في زيادة وتحقيق الأداء

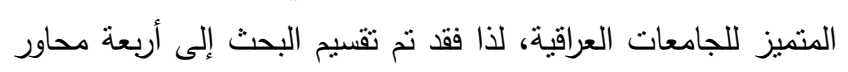

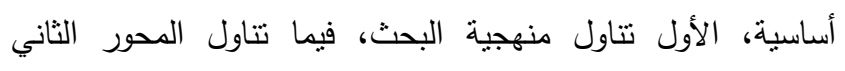

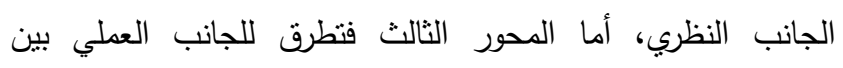

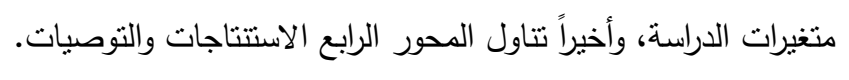
أولاً: مشكلة البحث:

تتبثق مشكلة البحث من تقويم الأداء المؤسساتي في بيئة التعليم الأهلي في الجامعات العراقية من خلال ثقييم الأداء للجامعات الأهلية

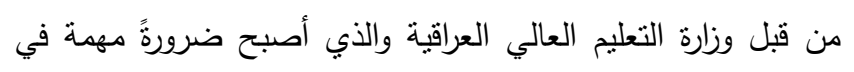

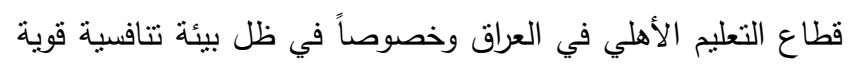

تعد حوكمة الثركات من أهم الموضوعات التي لاقت اهتماماً

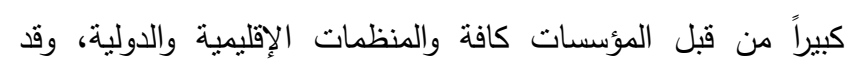

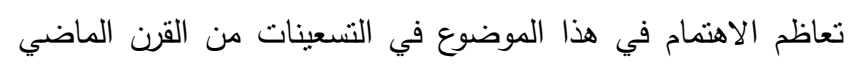

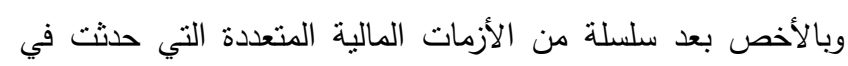

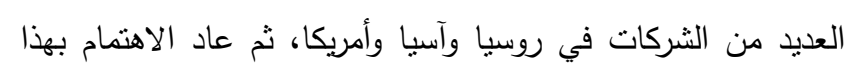

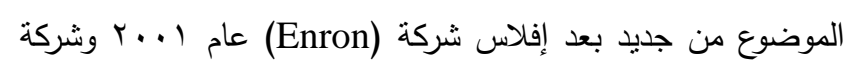
في عام r. Torld com)

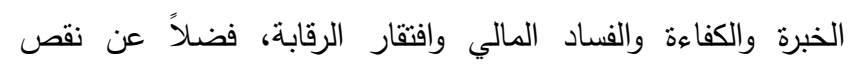

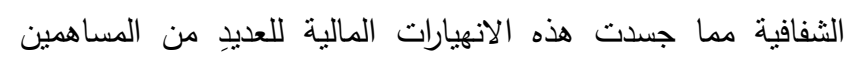

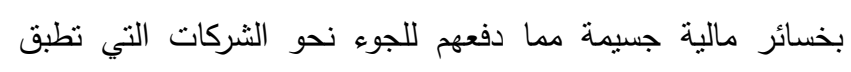

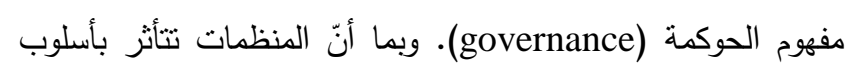
إدارتها، لذا فإن الحوكمة لها دور بارز في إكساب المنظمة إدارة جيدة 
أبعاد المتغير المستقل (حوكمة الثركات) على مصدر بركة(rr)، أما

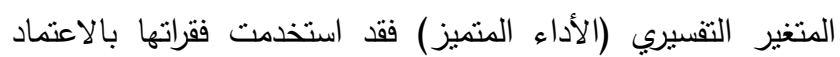

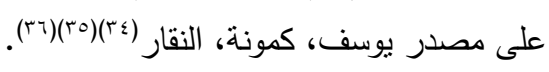

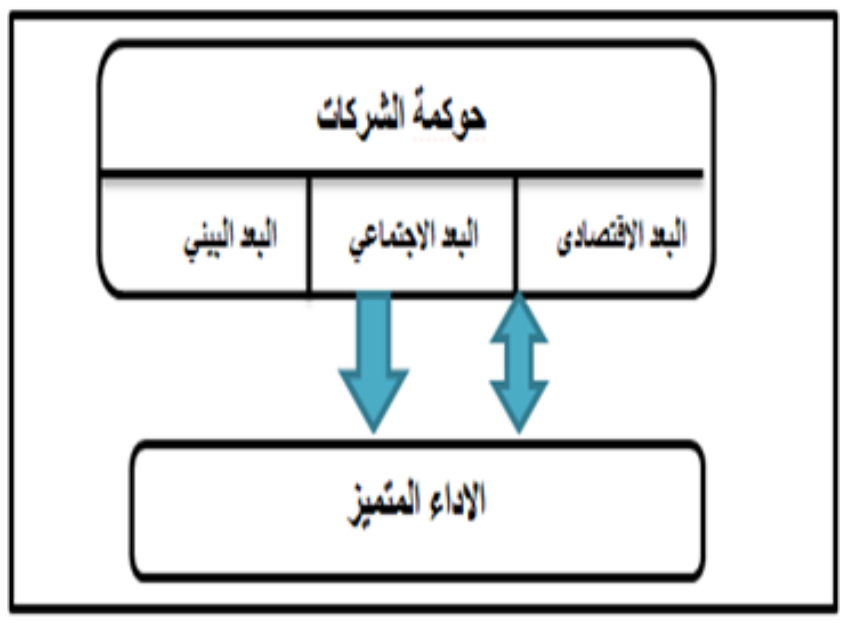

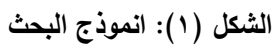

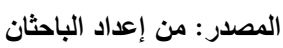

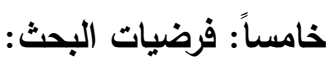

الفرضية الرئيسة الأولى: (توجد علاقة ارتباط ذات دلاتلة

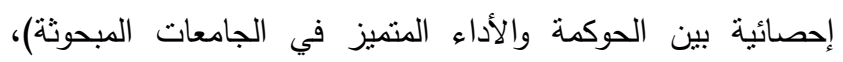

وتتفرع منها الفرضيات الفرعية الآتية: 1. توجد علاقة ارتباط ذات دلالة معنوية بين البعد الاقتصادي الأني والأداء المتميز.

r. توجد علاقة ارتباط ذات دلالة معنوية بين البعد الاجتماعي

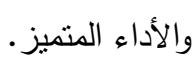

r. توجد علاقة ارتباط ذات دلالة معنوية بين البعد البيئي

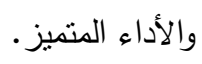

الفرضية الرئيسة الثانية: (يوجد تأثثر ذو دلالة إحصائية

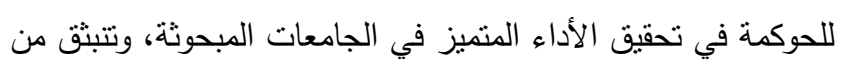
هذه الفرضية الفرضيات الفرعية الآثية:

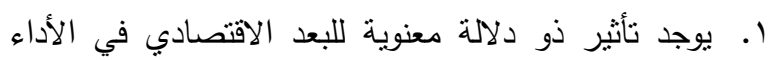
r. بوجد نأثير ذو دلالة معنوية للبعد الاجتماعي في الأداء

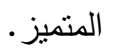
r. يوجد تأثير ذو دلالة معنوية للبعد البيئي في الأداء المتمبز .

\section{سادساً: مجتمع وعينة البحث:

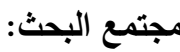

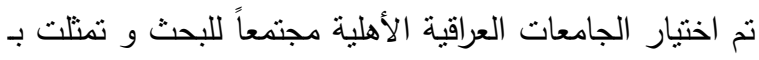
(كلية مدينة العلم، وكلية الإسراء، وكلية التراث) كونها تعد بيئة ملائمة

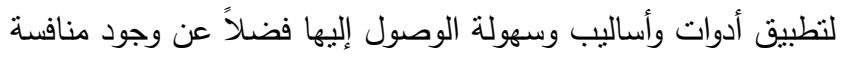
قوية جداً لتحقيق الأداء المتميز بين الجامعات العراقية الأهلية.
مع تزامن استحداث الجامعات الأهلية في ظل توجهات وزارة التعليم

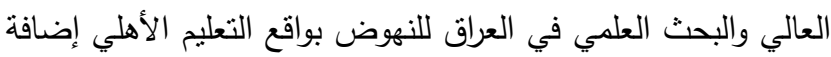

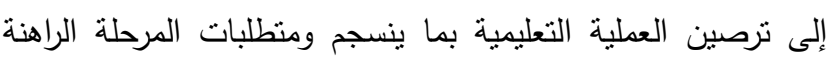

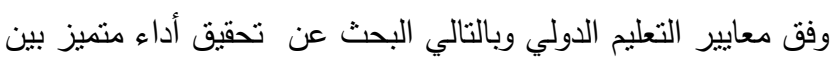
الجامعات العراقية الأهلية، ومن هنا تبرز مشكلة البحث في الجملة

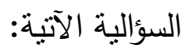

(هل يمكن للجامعات العراقية الأهلية أن تحقق الأداء المتميز من خلال الحوكمة بمجمل أبعادها)؟ ومن هذه الجملة تبرز الأسئلة الجئة الأنة

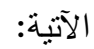

ما هو مفهوم الحوكمة في القطاع التعليمي؟ وماهي أبعادها؟ وأهية تطبيقها؟ ما هو مستوى اهنمام الجامعات مجتمع البحث بنطبيق

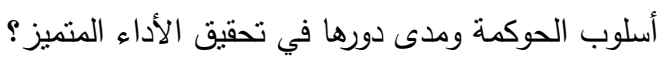

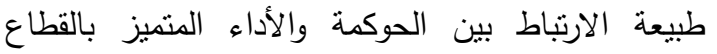

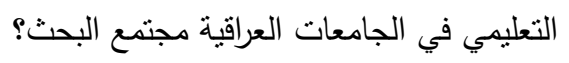
هل هناك أثر للعمليات الرشيقة في تعزيز القدرات الإبداعية

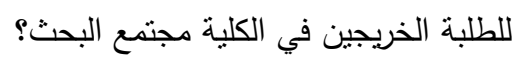

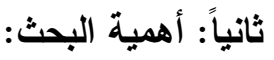

تتحور أهمية البحث في دراسة قواعد وأبعاد حوكمة الثركات

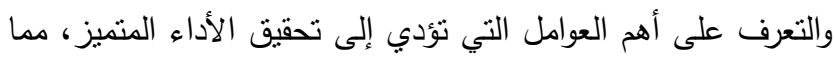

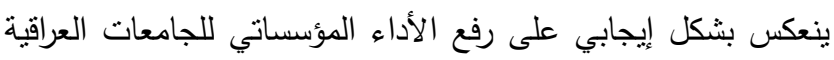

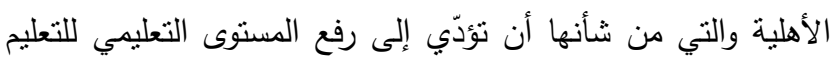

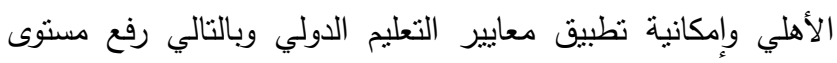
الجامعات الأهلية في العراق بشكل خاص والعالم بشكل عام.

ثالثاً: هلف البحث:

$$
\text { يهدف البحث إلى تحقيق الآتي: }
$$

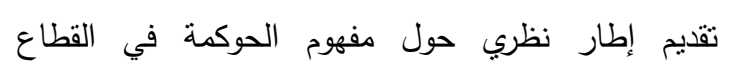

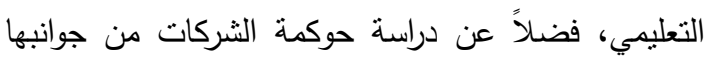
المختلفة والإثارة لأهمية تطبيقها. التعرف على مستوى تطبيق الحوكمة في الجامعات العراقية

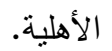
تحديد العلاقة التزابطية والثأثيرية بين متغيري البحث.

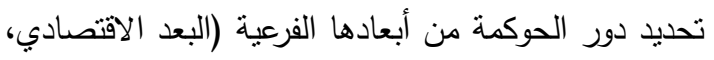

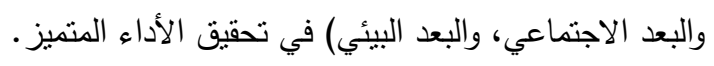

\section{إبعاً: مخطط البحث:}

يوضح الثكل (1) مخطط البحث الذي يعبر عن طبيعة

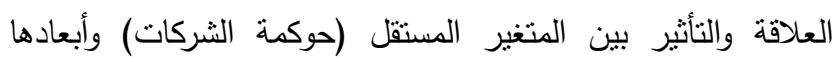

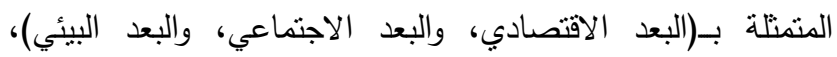
والمتغير التفسيري (الأداء المتميز). إذ اعتمد الباحثان في اختيار 
الاتحراف المعياري: استخدم فعلياً في تحديد مدى تشتت إجابات

أفراد العينة عن أوساطها الحسابية، إذ كلما انخفضت قيمته زادت درجة تركيز الإجابات عن الوسط الحسابي. ارتباط الرتب لسبيرمان: استخدم فعلياً في قياس مستوى العلاقة بين متغيرات البحث، ويشير إلى مجموعة من الارتباطات اللا معلمية، ويصلح في التعامل مع رتب القيم.

الانحدار البسيط: استخدم فعلياً في دراسة تأثنر المتغير المستقل البعد الاقتصادي والبعد البيئي والبعد الاجتماعي في المتغير

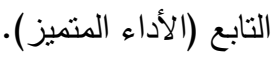

\section{المبحث الثاني: الجانب النظري:}

أولاً: حوكمة الثركات (Corporate Governance): ا ـ نشأة مفهوم حوكمة الشركات

تعود جذور الحوكمة إلى (Berle \& Means) اللذين يُعدان أولَ من تتاول موضوع فصل الملكية عن الإدارة وذللك في عام ( (9 ( ) )، وتأتي آليات الحوكمة لسد الفجوة التي يمكن أن تحدث بين مديري ومالكي الشركة من جرّاء الممارسات السلبية التي يمكن أن تضر بالشركة، وبالرغم من التغيرات الهائلة في نظم التعليم العالي على الصعيد العالمي فيبقى عمل الجامعات هو تدريس وتوليد المعارف الجديدة. وتعد الحوكمة ضرورة لعمل المنظمات ذات طبيعة العمل الأكاديمي الخاصة بالجامعات، لذا لا بد من التمبيز بين حوكمة الشركات وحوكمة الجامعات(بr). واستخدم مصطلح حوكمة الشركات مع بداية عقد التسعينات من القرن الماضي ومن ثم تزايد استخدامها بشكل واسع في السنوات الأخيرة وبعدها استخدمت بشكل شاسع من قبل الخبراء وبالأخص

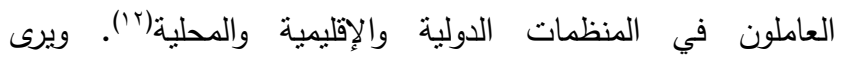
أنّ من خصائص الحوكمة الفاعلة في الجامعات هو وجود (Kezar) نظام فاعل يتصف بالحكم من جانب واحد بالثكل الذي يتتاسب مع ثقافة الجامعة، فضلاً عن أنّ هناك أدلةً عن حوكمة الحرم الجامعي التي تُعد الأكثر فاعلية عندما تعكس ثقافة الحرم الجامعي. وهنالك عدة تعاريف للحوكمة بين المختصين والمهتمين بتطبيقه، إذ عرفها على أنها "مجموعة من القوانين والنظم التي تهذف إلى (Ronald) تحقيق الجودة والتميز في الأداء عن طربق اختيار الأساليب المناسبة

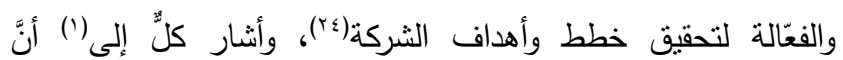
الحوكمة هي "النظام الذي يدل على وجود نظم تحكم العلاقات بين الأطراف الأساسية المؤثرة في الأداء". وعرّفها كلّ من (المشهداني والفتلاوي) بأنها "مجموعة من الإجراءات التي تتظم وتحكم العلاقة بين الإدارة والأطراف ذات العلاقة كالعاملين والزبائن والموردين والدائنين

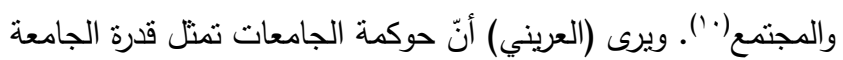
على تحقيق أهدافها بمسنوى أداءٍ عالٍ من الجودة وتحسين أدائها عبر
عينة البحث:

اختيرت عينة عشوائية مكونة من (.0) عضواً تدريسياً، وقد

جرى توزيع (·) استمارة استبانة على التدريسيين في كل من الجامعات العراقية المتمثلة بـ (كلية مدينة العلم وكلية الإسراء وكلية التراث) التي تعد موقع البحث، وتم توفير الوقت الكافي للإدلاء بآرائهر .

من نتائج الاستبيان اتضح أنّ الذين كانوا من الفئة العمرية

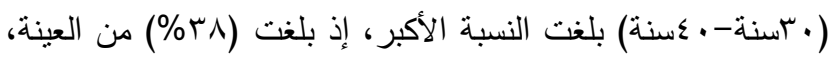
ثم تليها الفئة (• فأكثر) التي شكلت (דr\%) من العينة ثم تليها

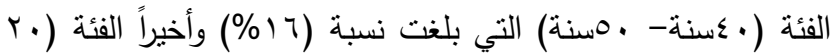
سنة -.r سنة) تمثلت النسبة (•(\%) من العينة، وعلى صعيد التحصيل العلمي فقد بلغت شهادة الماجستير النسبة الأكبر التي بلغت (ع\%\%)، وتليها شهادة الدكتوراه البالغة (7ء\%)، وهذا بشير إلى اختلاف الشهادات العليا التي تؤهلهم في الإدارة والتعليم الجيد للكليات عينة البحث، أما على صعيد اللقب العلمي لأفراد العينة، فقد حصل أستاذ مساعد النسبة الأكبر التي بلغت (7٪\%)، ويليها مدرس التي بلغت نسبة (ب\%\%)، ثم مدرس مساعد التي بلغت نسبة

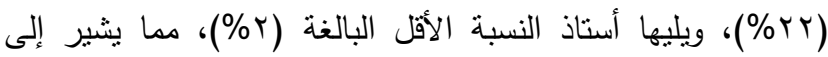
التتوع العالي للألقاب العلمية الخاصة بأفراد العينة. وأخيراً تضمن محور مدة الخدمة في الكلية المبحوثة فقد بلغت الفئة (7 ا سنة فأكثر)

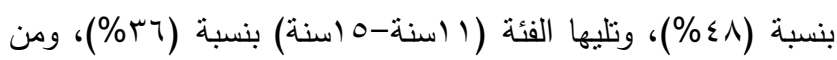
ثم الفئة (1 سنة-هسنوات) بنسبة (Y (\%\%)، وأخيراً الفئة (Tسنوات • اسنوات) التي بلغت نسبة (ع\%)، مما يؤكد على امتلاك عينة البحث خبرات ومهارات متتوعة في العمل بالكلية.

$$
\text { سابعاً: حدود البحث: }
$$

الحدود المكانية: جرى البحث في عدد من الجامعات العراقية

$$
\text { الأهلية لإجراء الجانب العملي من البحث. }
$$

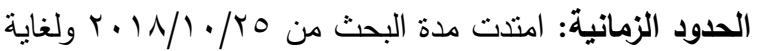

$$
. r \cdot 11 / 11 / r \text {. }
$$

الحدود البشرية: شملت عينة البحث (•) فرداً تملي عليهم مواقع المسؤولية العلمية والأخلاقية تحقيقَ التميز في مستوى الأداء في لئي الجامعات موضع البحث. ثامناً: أساليب التحليل الإحصائي: استخدمت مجموعة من الأساليب الإحصائية في معالجة البيانات الواردة في الاستبانة وتبويبها باستخدام البرنامج الإحصائي الجاهز (SPSS) لإجراء التحليلات الإحصائية الآتية منها(بr) الوسط الحسابي: استخدم فعلياً في وصف وقياس مستوى متغيرات البحث لدى أفراد العينة. 
(الرقابة الداخلية، الذي يشمل التدقيق الداخلي، ولجان التنقيق، وإدارة المخاطر ، والموازنة التخطيطية، وتدريب الموظفين). البعد الاجتماعي والقانوني: والذي يثير إلى طبيعة العلاقة ونكة

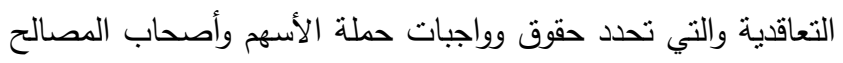
المختلفة من ناحية والمديرين من ناحية أخرى والمسؤولية الاجتماعية

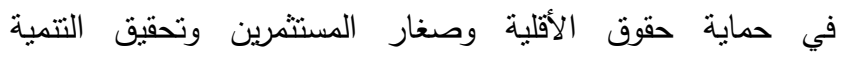
الاقتصادية ويتضمن هذا البعد: (الهيكل التظظيمي، الذي يشمل تحديد

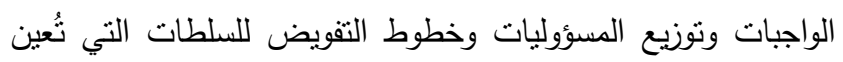

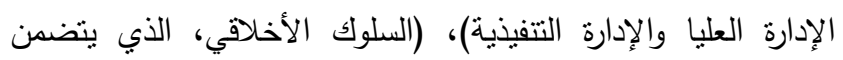

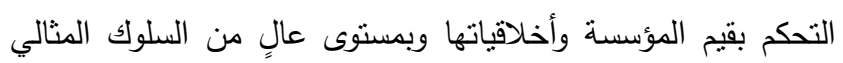
فيها والتقييد بقواعد السلوك المهني).

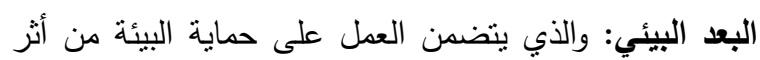

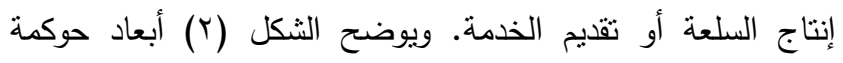

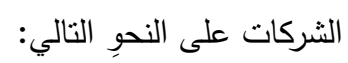

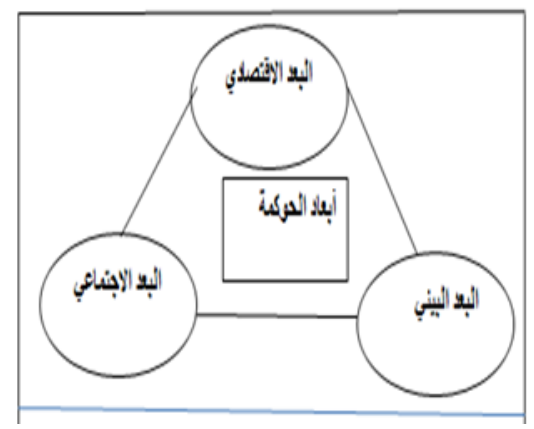

الثكل (r): أبعاد حوكمة الشركات.

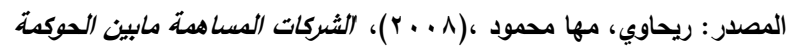

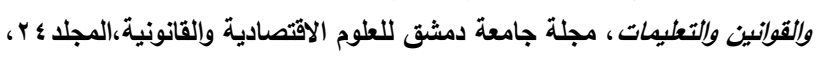

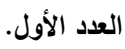

\section{ع. الأطراف المعنية بتطبيق حوكمة الثركات}

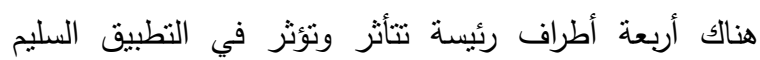

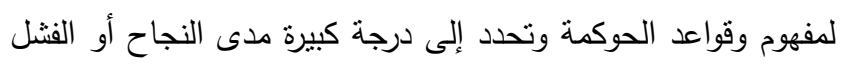

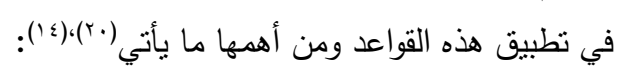
1. المساهمون (Shareholders): هم الذين يقدمون رأس المال

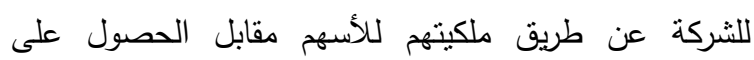

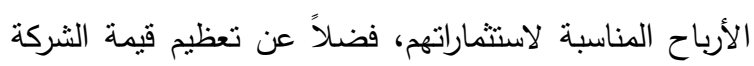

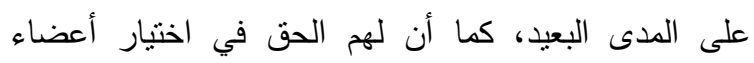
مجلس الإدارة المناسبين لحماية حقوقهم.

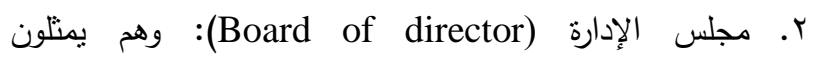
المساهمين وأيضا الأطراف الأخرى مثل أصحاب المصالح

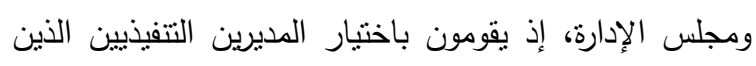

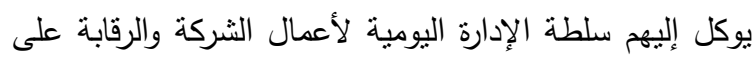

اتباع أساليب مناسبة وخطط فاعلة من خلال الإدارة الجيدة

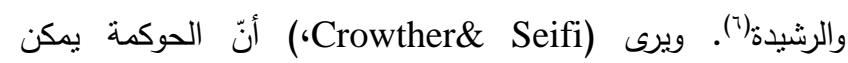

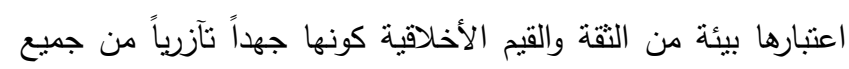

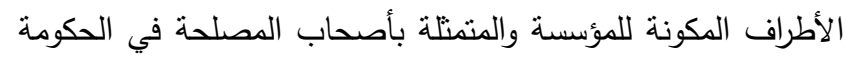

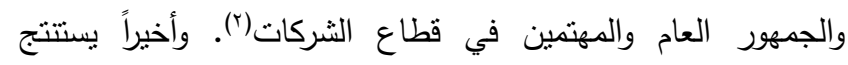
الباحثنان أنّ الحوكمة لا تشير إلى ما تفعله المؤسسات وإنما إلى كيفية

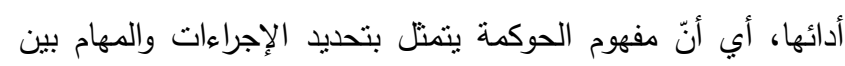

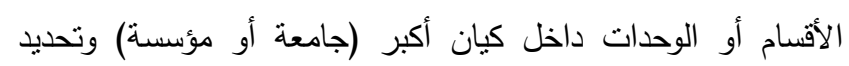

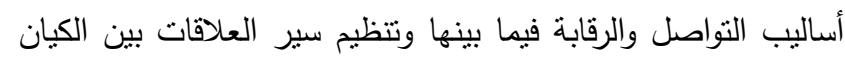

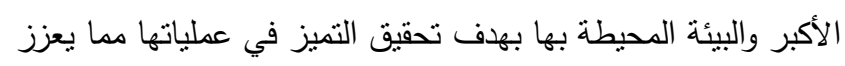

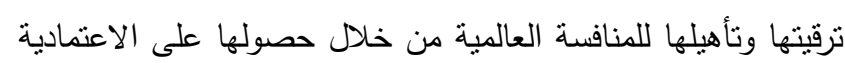

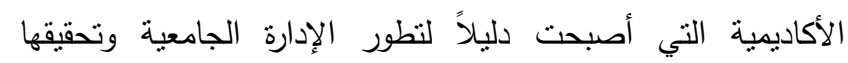

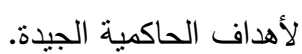

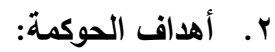

تسعى قواعد الحوكمة إلى تحقيق مجموعة من الأهداف التي يمكن تلخيصها بالآتي(1)، (10): تحقيق الثفافية نتيجة العمل وفق الضوابط والآليات التي تتسم بالوضوح وبالتالي تمكن العاملين من ممارسة الأعمال

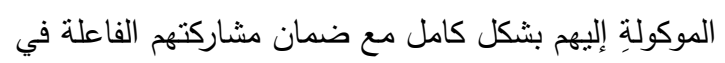
جميع الأنشطة داخل وخارج نطاق الجامعات. تعزيز فاعلية الجامعات وتكوين بيئة عمل صالحة نظراً لزيادة كفاءة أدائها الداخلية والخارجية.

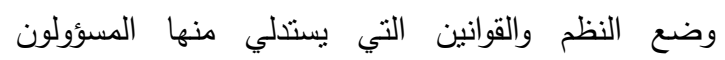
وأصحاب القيادات في الجامعات في نولي مهامهم الإدارية مما يضمن تحقيق العدالة لكافة الأطراف المعنية.

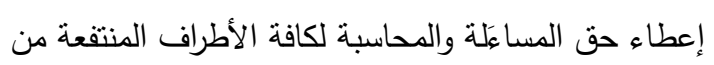

$$
\text { وجود الجامعات. }
$$

تفعيل المشاركة الجماعية في عملية صنع القرار وذللك عبر الجات الإداء

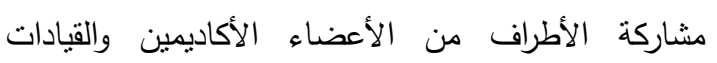
الإدارية والطلاب في تلك العمليات.

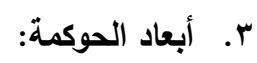

هناك العديد من الأبعاد المختلفة للحوكمة والتي تتمثل في

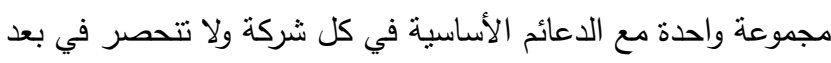
واحد هو الربح أو الخسارة وإنما هو ثلاثي الأبعاد تتمثل في الآتي (ro):

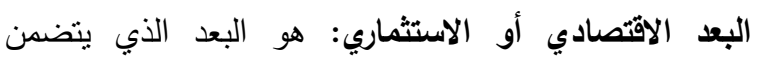

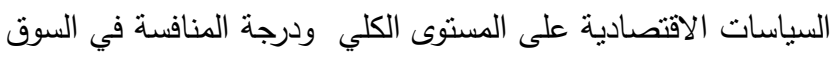

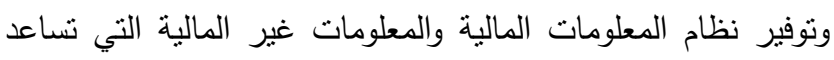

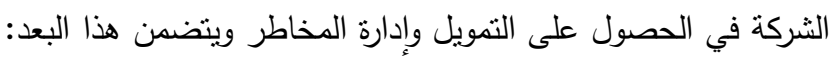

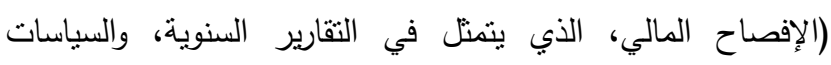
المحاسبية المتبعة، وتقارير التدقيق الخارجي، ومقاييس الإنجاز)، 
أن يتحقق من تفاعل خمسة مكونات رئيسة هي (مشاركة العاملين، وفريق العمل الموجه ذاتياً، وإدارة الجودة الثاملة، وتكنولوجيا الإنتاج

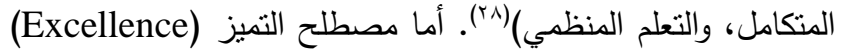
فقد بدأ الاهتمام به كمفهوم في مطلع الثمانينات من القرن العشرين حين قام (Peters \& Waterman) بتأليف كتابهما الششهور بعنوان البحث عن التميز (In search of excellence)" في عام 1919 والذي جاء كرد فعل نتيجة تميّز الشركات اليابانية منذ عقد الستينات والسبعينات، وقد درس كل منهما عدداً من الثركات الأمريكية المتميزة وحددوا عوامل نجاحها على وفق معايير التميز الححددة والمعتدة في

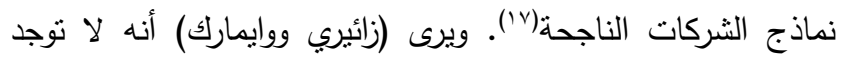
هناك شركات منميزة بل شركات تجاهد من أجل تحقيق التميز وذلك الكات من خلال التخويل ودعم السلطات والمقارنة المرجعية والتحسين المستمر، ورغم أن ذلك لا يكفي بمفرده لبقاء الثركة إلا أنه يمنل

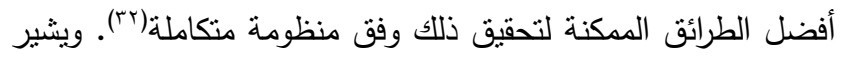

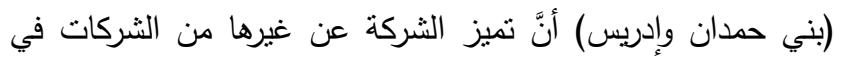

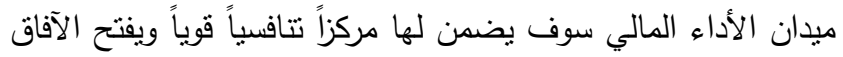

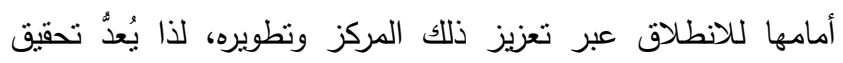

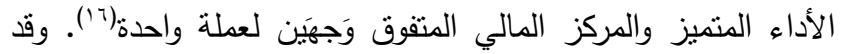

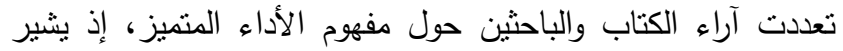

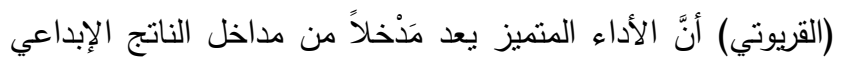

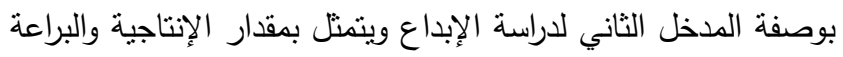

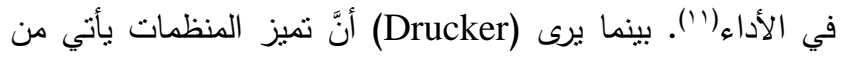
المعرفة التي يمتلكها الأفراد فهي محور الأعمالِ التي تقوم بها هذانه

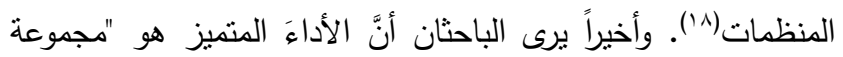

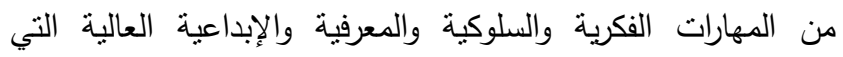
يمتلكها العاملون في الثركة والتي تسعى نحو توظيفهم لإنجاز مهام أعمالها بالثكل الذي يفوق خططها الموضوعة وبالتالي تقديم منتجات وأعمال تتسم بالتميز والأصالة وبالتالي تحقق أهدافاً متصاعدة التهات

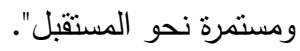

\section{r. أهمية الأداء المتميز}

يشير (العزاوي) إلى أنَّ أهمية الأداء المتميز تعكسها المعاني الهي

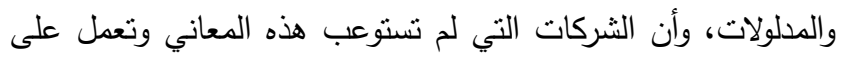

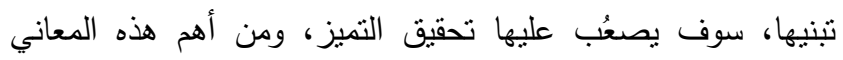

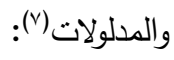
توجيه النتائج: ينم الحصول على النتائج الني نسعد أصحاب المصالح للشركة. تركيز الزيون: يُنْنئئ قيمة الزبون المستقبلية والمستمرة .

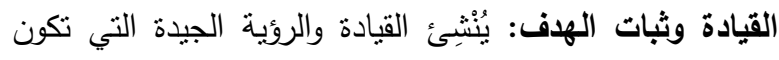
مقترنة بثبات الهدف.
أدائهم، فضلاً عن قيامهم بعملية رسم السياسات العامة للشركة والمحافظة على حقوق المساهمين. r. الإدارة (Management): تعد الإدارة المسؤولة عن الإدارة الفعلية للشركة وتقديم تقارير الأداء إلى مجلس الإدارة فضلاً

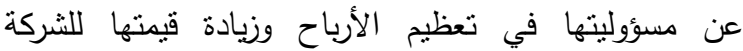
والإفصاح والثفافية في المعلومات التي تتشرها للمساهمين.

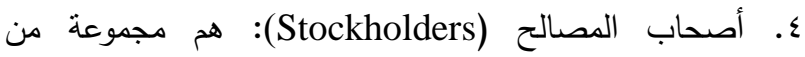
الأطراف الذين يكون لديهم مصالح داخل الثركة منل الدائنين

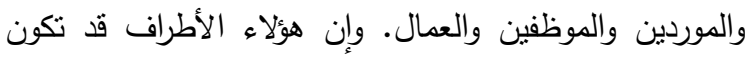
لديهم مصالح متعارضة ومختلفة في بعض الأحيان مثل

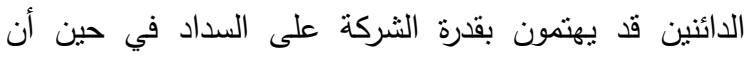

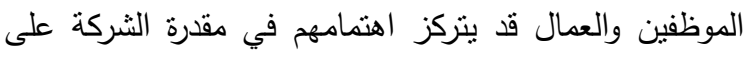

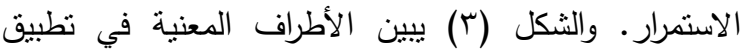

الحوكمة.

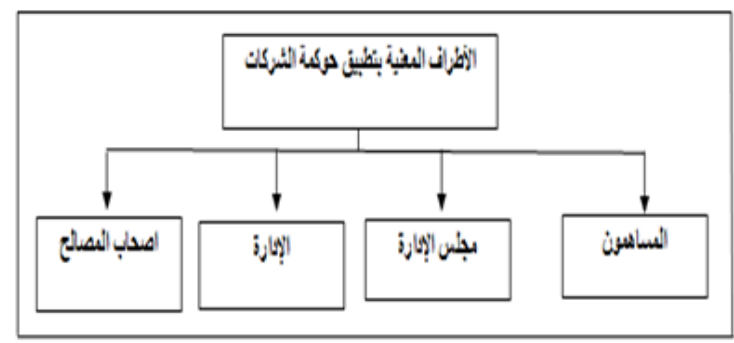

الثكل (ץ): الأطراف المعنية في تطبيق الحوكمة.

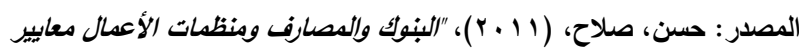

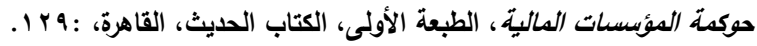

ثانياً: الأداء المتميز (Excellence Performance): 1. الـ مفهوم الأداء المتميز

يُعد مفهوم الأداء المتميز من الموضوعاء الميزيز الإدارية الحديثة التي

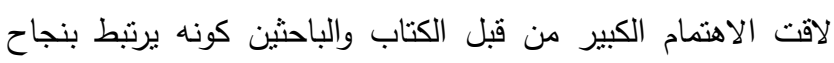
الأفراد وتفوقهم سعياً إلى تحقيق أهداف الثركة المستقبلية الموجودة في بيئة تحكمها المنافسة والنطورات الثقنية الهائلة وبالتالي سوف يكون التاني

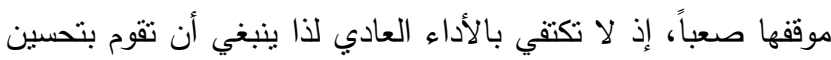

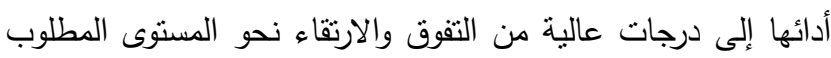

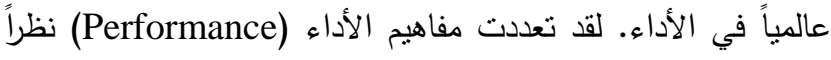

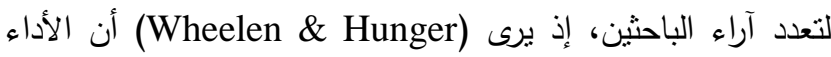
يمثل النتيجة النهائية لنشاط الثركة والذي يركز على أهداف البقاء

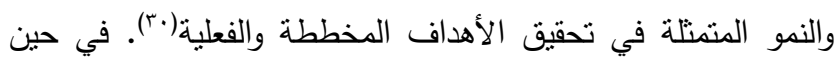

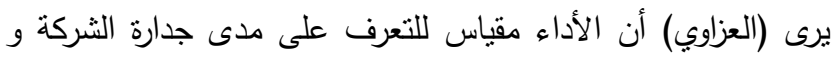

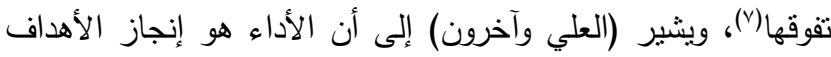

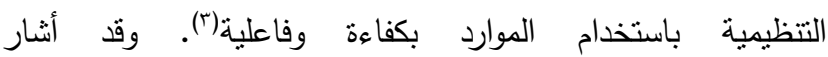

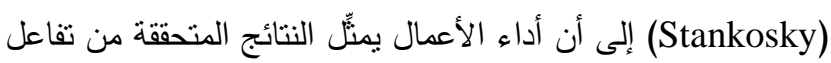
أنشطة المنظمة ومواردها، وأضاف بأن الأداء المتميز للمنظمة بمكن الاعمان 
المهارات الفكرية: هي القابلية على الرؤية والثمولية للمنظمة ككل وربط أجزاء الموضوع ببعضها وهي مطلوبة أكثر في الإدارة العليا. المهارات الإنسانية: وتعني القدرة على التعامل مع الآخرين وهي القالي مطلوبة بصورة متساوية في جميع المستويات الإدارية. •المهارات الفنية: وهي اكتساب مهارة اللغة والمحاسبة واستعمال الحاسوب وهي مطلوبة أكثر في المستويات الإدارية. التكيف (Adjustment): عملية ديناميكية مستمرة يهدف بها الفرد إلى أن يغير سلوكه ليحدث علاقة أكثر نوافقاً وتوازناً مع البيئة.

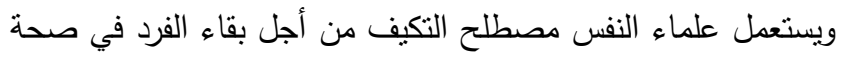
نفسية وبسبب المنافسة المستمرة يحتاج العاملون إلى اكتساب مهارات ومعارف جديدة تتناسب مع المنطلبات الجديدة في العمل (^). الثقافة (Culture): تعد الركيزة الأساس لدراسة وفهم

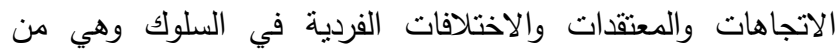

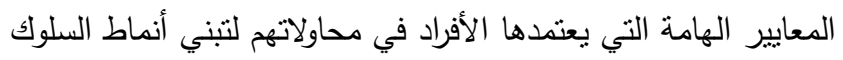

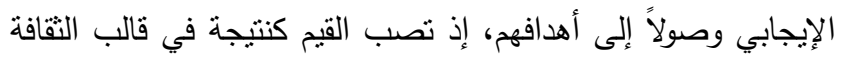

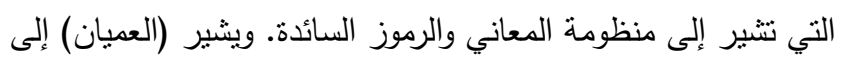
أن الثقافة هي الكائن المعقد الذي يمثل المعرفة والعقيدة والفن

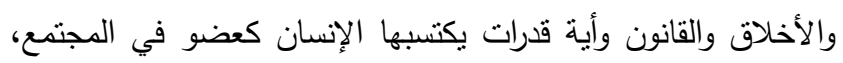
وتتكون الثقافة من ثلاثة عناصر رئيسة هي (ه): • المبادئ والقيم والأفكار التي تنتلور لدى الأفراد.

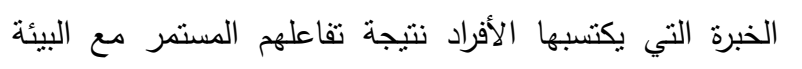
المحيطة بهم لمبه القدرات والمهارات الفنية التي اكتسبها الفرد في حياته.

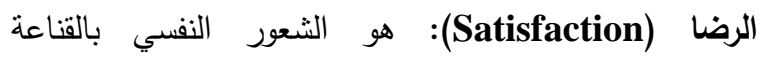

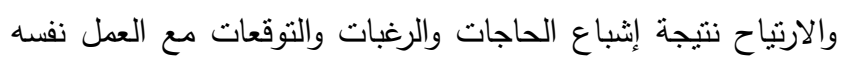
وبيئة العمل، والرضا الوظيفي هو تجميع للظروف النفسية والفسيولوجية والبيئية التي تحيط علاقة الموظف بزملائه ورؤسائه وتتوافق مع شخصيته التي تجعله يقول بصدق: أنا سعيد بعملي (rr)

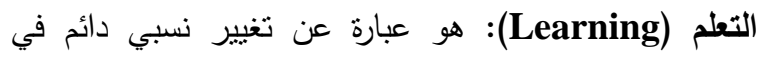
مستوى ونوع السلوك نتيجة التجربة ومن ثم الحصول على على المهارات

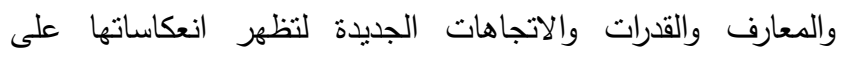

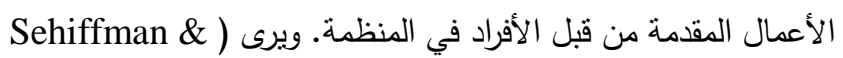

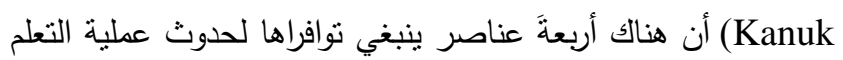

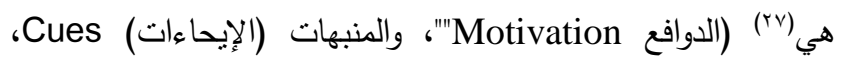
والاستجابة Response" والتعزيز (Reinforcement) ) )

\section{ـ. ـ العوامل الموئثرة في تحقيق الأداء المتميز}

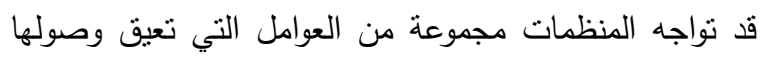

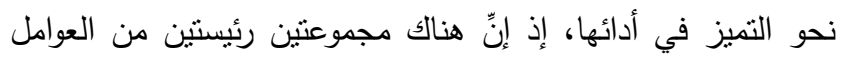

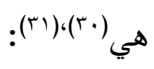

الإدارة بالحقائق والعمليات: تُار الثركة عبر مجموعة أنظمة معتمدة على الحقائق والعمليات. تطوير تدخل العاملين: بساعد مساهمة العاملين في العملية الإنتاجية وتطويرها.

التعلم والإبداع والتحسين المستمر: يتحدى الوضع الراهن للشركة ويسبب تغييراً في بناء فرص التحسين والإبداع. تظوير الثراكة: يعمل على تحسين وتطوير الثراكات وزيادة القيمة المضافة. المسؤولية الاجتماعية للثركات: يتجاوز الإطار التنظيمي

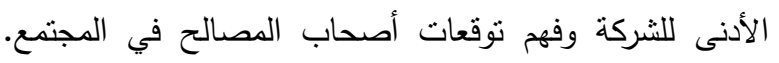

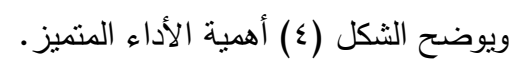

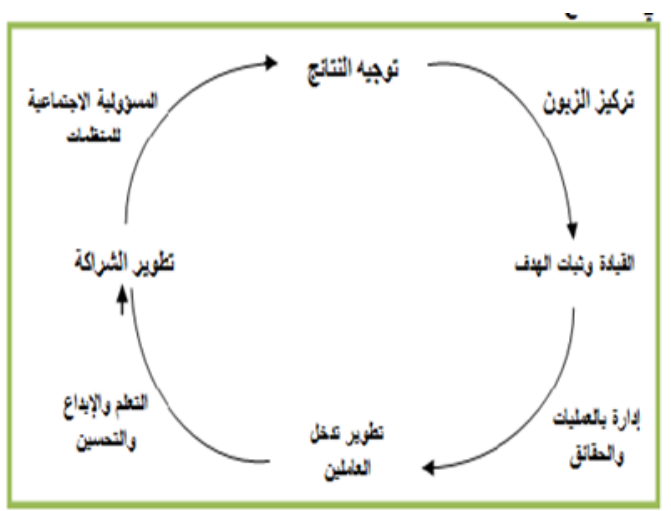

شكل (؛): الركائز الأساسية للأداء المتميز.

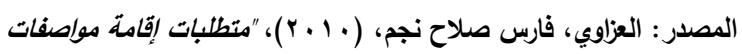

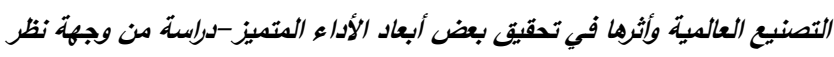

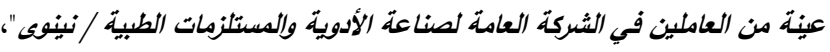
r. أبعاد الأداء المتميز تتطلق أبعاد الأداء المتميز من أهمية الموارد البشرية باعتبارها أثمن شيء موجود في حياة المنظمات وعليها تقع مسؤولية تطورها والحفاظ على مكانتها ووصولها إلى التميز ، لذلك حدد الباحثان بعض فئ

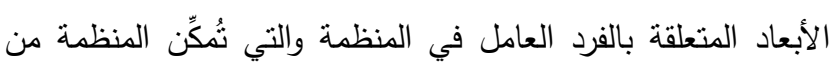
تحقيق الأهداف الاستراتيجية بأدائها المتميز التي تتطوي أساساً على بلى تحقيق عمليات الانسجام بمستوى عالٍ ومختلف عن الآخرين ومن ثنّ خلق القيمة للعمل الذي يؤديه نتيجة تكيفه ورضاه وتعلمه للعمل بالشكل الصحيح، وفيما يلي سرد أو توضيح لهذه الأبعاد(r')": المهارات (Skills): هي مجموعة من الصفات والسمات في شخصية الأفراد التي تمكنهم من الإدارة الفعالة للعمل إذ يمكن للمهارات الجيدة خلق عالم من الاختلاف في كفاءة وأداء المنظمة(21. كما يثير (العامري والغالبي) بأنها "القابلية على ترجمة المعرفة إلى الى أفعالٍ ينتج عنها أداء منميز" المهارة هي أداء مهمة ما بطريقة صحيحة فهي تعبر عن التمكن من إنجاز مهمة معينة بكيفية محددة

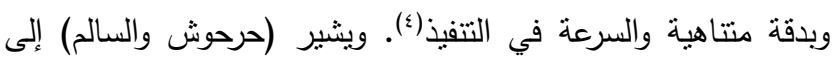
المهارات التي ينبغي على كل مدير أن يتمتع بها وهي('9): 


\begin{tabular}{|c|c|c|c|c|}
\hline \multicolumn{5}{|c|}{ الجدول (r): التحليل الوصفي لإجابات العينة لمتغير الحوكمة. } \\
\hline $\begin{array}{c}\text { النسية } \\
\text { \% }\end{array}$ & المعراف & المتوسط & السؤال & المتغيرات \\
\hline$\wedge v, T$ & $\cdot, 7$ & $\varepsilon, r \wedge$ & واستغلالها الأمتل. & \multirow{7}{*}{ 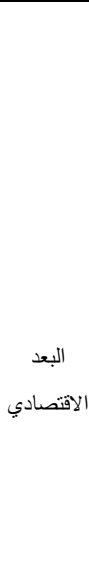 } \\
\hline$\wedge 9,7$ & $\cdot, \uparrow$ & $£, \leqslant \wedge$ & 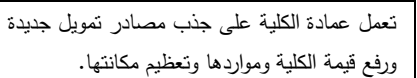 & \\
\hline $91, r$ & $\cdot, 01$ & $\{, 07$ & بالفساد المالي والإداري التي تواجه الكلية. تلفيض المخاطر المتعلقة & \\
\hline$q_{\cdot, \cdot} \cdot$ & $\cdot, 70$ & $\leq, 0$ & نوفي عمادة الكلية الثفافية والدقة والوضوح والنزاهة & \\
\hline 10,1 & $\cdot, V$ & $\varepsilon, \Upsilon \wedge$ & 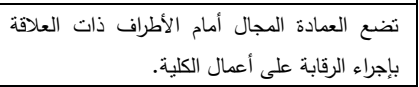 & \\
\hline 10,1 &., $0 \mathrm{~V}$ & $\varepsilon, \Upsilon_{\wedge}$ & تتوفر لاى الكلية نظم محاسبية فاعلة تضمن تشغيل الخاذ القرار الإداري بكفاءة عالية. & \\
\hline ᄉт, \{ & אד, • & $\varepsilon, r T$ & 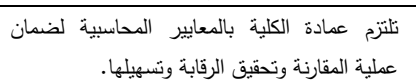 & \\
\hline$\wedge$, & זוד, & $\varepsilon, \varepsilon$ & \multicolumn{2}{|l|}{ المجموع } \\
\hline$\lambda v, T$ & $\cdot, T \leq$ & $\varepsilon, r \wedge$ & الكلية. & \multirow{9}{*}{ الاجنماعي } \\
\hline 10,1 & $\cdot, V \Gamma$ & $\varepsilon, Y \wedge$ & 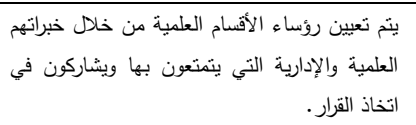 & \\
\hline$\wedge 9, r$ & $\cdot, 71$ & $\{, \leqslant 7$ & غيرها. & \\
\hline Ar, & $\cdot, \wedge$ & $\varepsilon, 11$ & 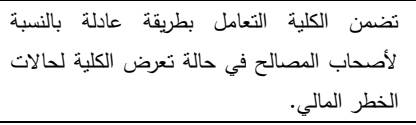 & \\
\hline$\wedge 7, \varepsilon$ & $\cdot, 70$ & $\varepsilon, r Y$ & 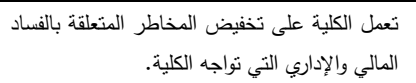 & \\
\hline$\wedge r, \tau$ & $\cdot, \wedge$ & $\varepsilon, 1 \wedge$ & مستوى الثفافية. & \\
\hline$\wedge r, r$ & $\cdot, \wedge \vee$ & $\leq, 17$ & 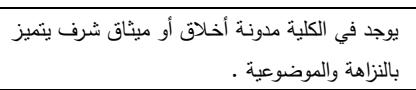 & \\
\hline$\wedge \varepsilon, \wedge$ &., 07 & $\varepsilon, r \leqslant$ & 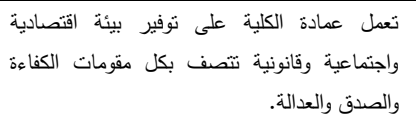 & \\
\hline$\wedge т, \varepsilon$ & $\cdot, 70$ & E,r & 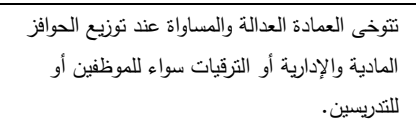 & \\
\hline 17,70 & . TV & $\varepsilon, r T$ & المجموع & \multirow{6}{*}{ البعد البيئي } \\
\hline$\wedge r, \tau$ & $\cdot, \wedge V$ & $\varepsilon, 1 \wedge$ & 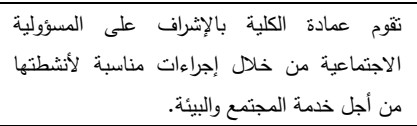 & \\
\hline $\mathrm{VA}, \varepsilon$ & $1,1 r$ & r,QT & تلتعى عمادة الكلية إلى وضع خطط تعمل من أجل التصديد التصدي & \\
\hline 10,7 & $\cdot, \lambda 1$ & $\varepsilon, \Upsilon_{\curlywedge}$ & لدى الكلية خطة لموئتمرات وندوات علميـة تتضمن & \\
\hline$\wedge r, \tau$ & $\cdot, \lambda \vee$ & $\varepsilon, 11$ & 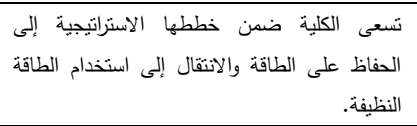 & \\
\hline$\lambda_{0, r}$ & •, & $\leq, r q$ & 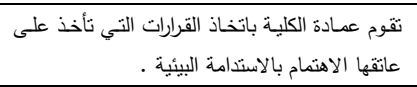 & \\
\hline 10,10 & $\cdot, V r$ & $\varepsilon, r^{\prime}$ & المجموع & \\
\hline $10, \leqslant \wedge$ & דוז, & $\varepsilon, r_{q}$ & الحوكــــة & \\
\hline
\end{tabular}

1. العوامل الثخصية: هي العوامل التي ترتبط بالفرد العامل والتي

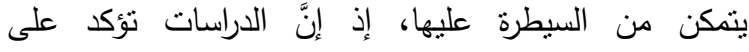

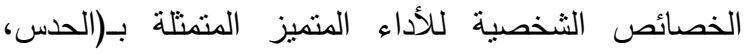

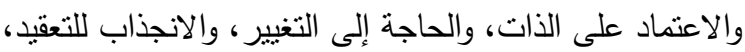

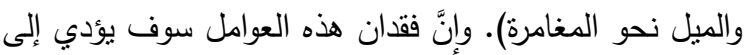
تنشكيل عائق أمام الأفراد الذين يسعون نحو تحقيق الأداء - المتميز r. العوامل المنظمية: هي العوامل التي نرتبط بالمنظمة ولا يتذخل الفرد في إيجادها ومنها: • البيئة البيروقراطية: هي البيئة التي تتسم بالتعقيد والروتين وبتعدد المستويات الإدارية وتكون بطيئة الحركة وتعمل على إخراج الأفراد المتميزين من المنظمة بشكل أسرع من جلبهه إليها. • التعقيد في التعليمات والقوانين: تعد القوانين والتعليمات وسيلة وليست غاية، إذ إنَّ الرقابة الإدارية في بعض المنظمات فلات نقانصر

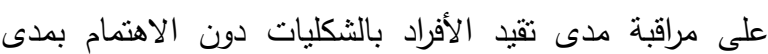
مساهنتهم في تحقيق الهذف منها.

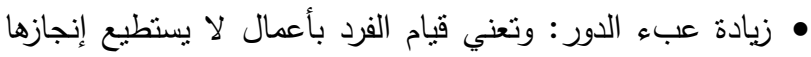
في الوقت المتاح مثل إلقاء المحاضرات واعداد البحوث ونشرها، وتقديم الاستشارات، والمشاركة في اللجان. كما بَيَّن (المشهداني) مجموعة من المعوقات التي تمنع المنظمة

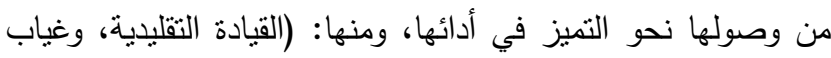

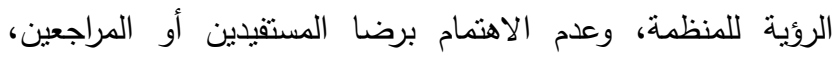

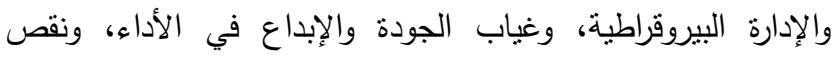

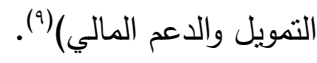

\section{المبحث الثالث: الجانب العملي للبحث} وصف وتثخيص متغيرات البحث والتحليل الأولي للنتائج يتتاول هذا المبحث وصف وتتخيص متغيرات البحث والتحليل الأولي للنتائج وتفسيرها على وفق إجابات عينة البحث واختبار

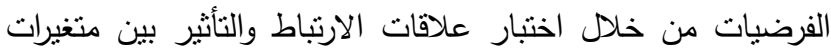
البحث، وقد تم استخدام وسائل التحليل الوصفي (الوسط الحسابي،

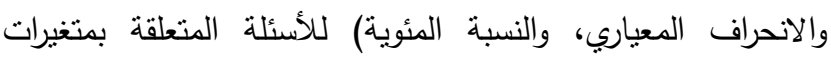
البحث لغرض معرفة اتجاه الإجابة. تتتاول هذه الفقرة وصفاً عاماً لآراء عينة البحث حول متغيرات (الحوكمة) في الكليات المبحوثة، وهذه المتغيرات هي (البعد

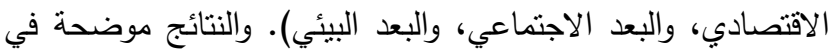


الإجابات من بين جميع الفقرات، إذ كان الانحراف المعياري (آ, ·)

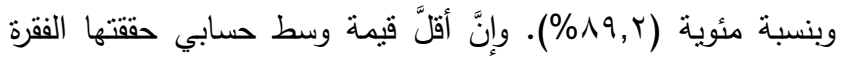

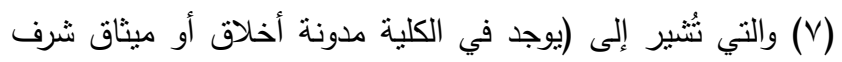

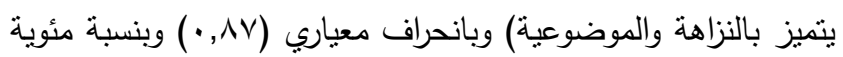

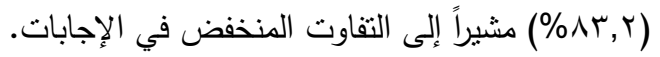

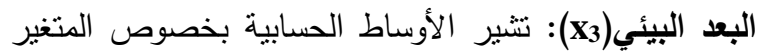

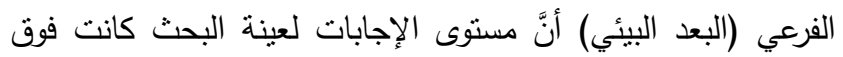

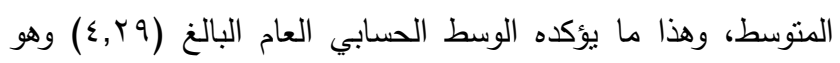

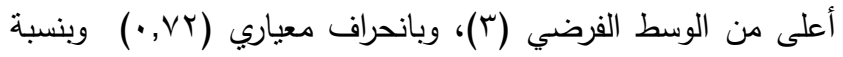
مئوية (10,10\%) وهذا يشير إلى تفاوت منخفض في الإجابات مما

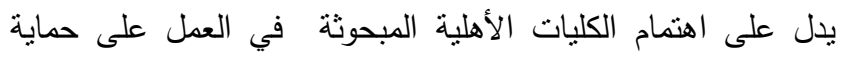

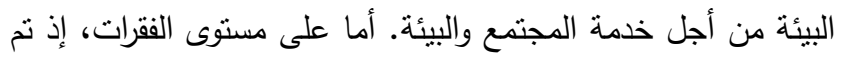
قياس هذا المتغير بالفقرات (1-0) فقد تراوحت قيم الوسط الحسئة الحسابي بين أعلى قيمة حققتها الفقرة (†) التي تثتير إلى (لدى الكلية خطة لمؤتمرات وندوات علمية تتضمن حماية الموارد الطبيعية ضد تلوث

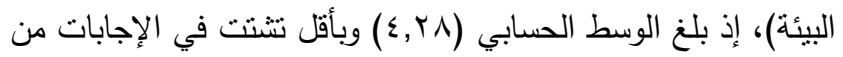

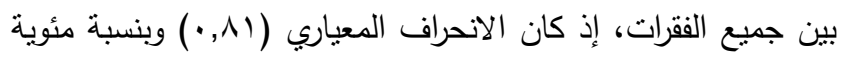

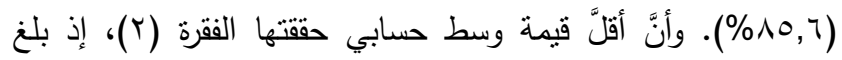

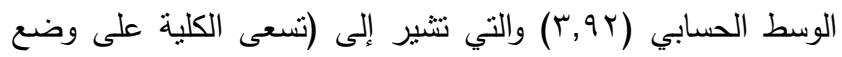

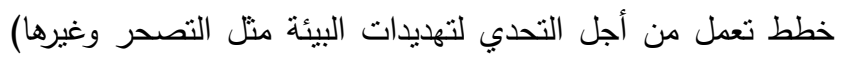

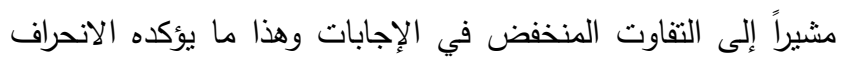

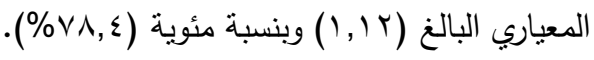

\section{ثانياً: تحليل إجابات عينة البحث لمتغيرات الأداء المتميز}

ضمن هذه الفقرة سيتم وصف وتتخيص آراء عينة البحث حول

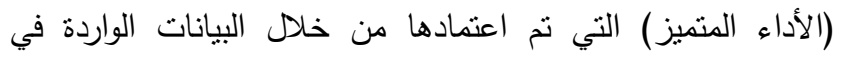

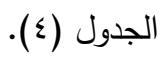

الجدول (؛): تحليل إجابات العينة لمتغير الأداء المتميز.

\begin{tabular}{|c|c|c|c|}
\hline النوية النسبة & المعياري & المتوسط & السؤال \\
\hline 14 & וד, & \&, & تفاعلها مع المجتمع الكلية نحو تقديم أفضل الإنجازات العلمية من خلال \\
\hline$\Delta v, r$ & .,79 & $\{, r 4$ & 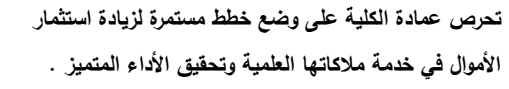 \\
\hline 14 & סי, • & \&, & تحرص الكلية على رفع مستوى التعليم من خلال استخدام التعليم \\
\hline \$४, & זי, • & & 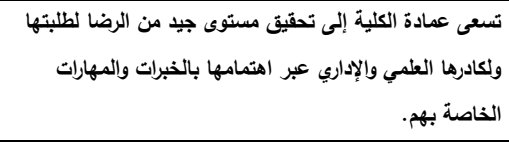 \\
\hline$\wedge \wedge$ & , & $\{, \xi$ & تحرص الكلية على رفع الروح المعنوية للطلبة من خلال تنفيذ \\
\hline$\wedge,, \xi$ & , , 0 & $\varepsilon, \cdot r$ & 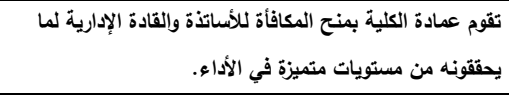 \\
\hline \& & •, V V & $\{, r T$ & تعتل عمادة الكلية على تثجيع موظفيها وكادرها التدريسي في \\
\hline
\end{tabular}

يشير الجدول (T) إلى قيم الأوساط الحسابية والانحرافات

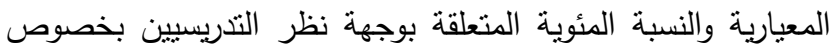

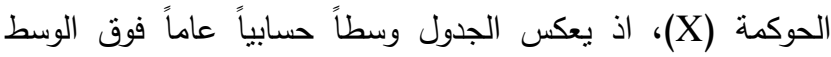

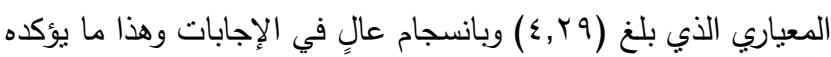

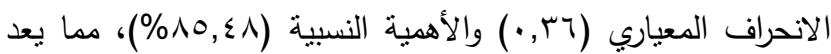
مؤشراً منخفضاً في الإجابة ويدل على حرص اهتمام الكليات المبحوثة بكل ما تمنلكه من حوكمة واستخدامها بشكل كفؤ وفاعل. إذ شملت الإنابه تلك الحوكمة ما يأني:

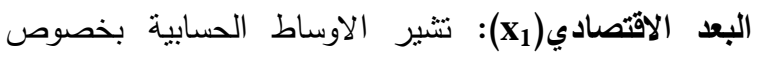
المتغير الفرعي (البعد الاقتصادي) أنَّ مستوى الإجابات لِعيّنة البحث

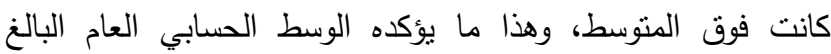

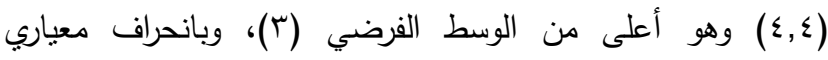

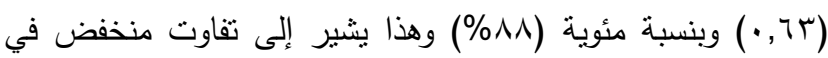

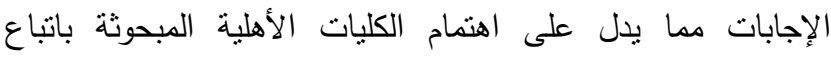
السياسات الاقتصادية على المستوى الكلي ودرجة المنافسة وتوفير نظام المعلومات المالية والمعلومات غير المالية التي تساعدها في ولئي

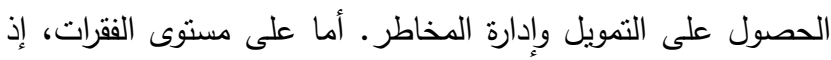
تم قياس هذا المتغير بالفقرات (V-1) فقد تزاوحت قيم الوسط الحسابي بين أعلى قيمة حققتها الفقرة (r) التي تشير إلى (تعمل عمادة الكلية على تخفيض المخاطر المتعلقة بالفساد المالي والإداري التي تواجه

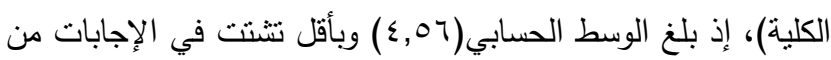

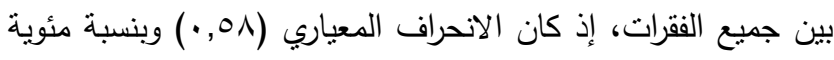

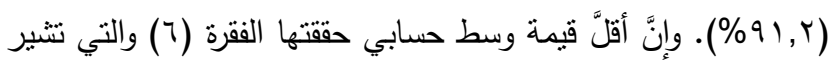
إلى (تتوفر لدى الكلية نظم محاسبية فاعلة تضمن تشغيل عملية اتخاذ

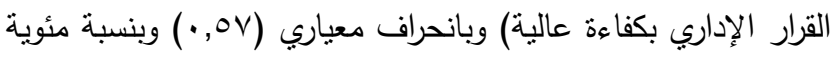

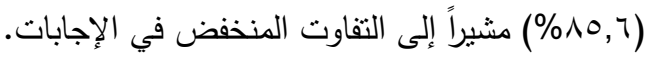

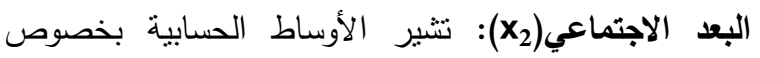

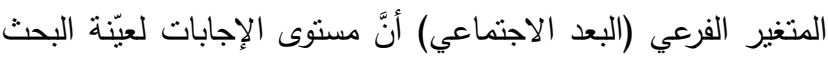

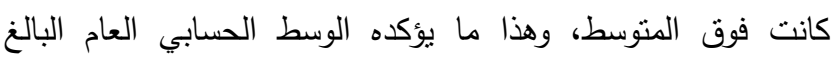

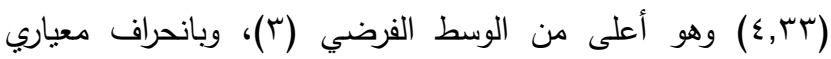
(TV) في الإجابات مما يدل على سعي الجامعات الأهلية المبحوثة في

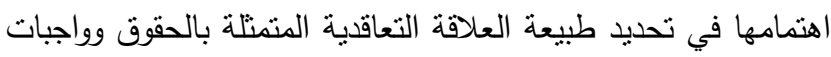

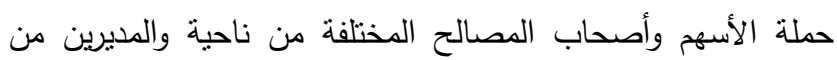
ناحية أخرى والمسؤولية الاجتماعية في حماية حقوق الأقلية وصغار

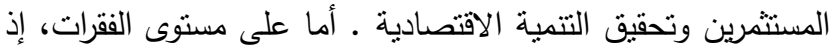
تم قياس هذا المتغير بالفقرات (1-9) فقد تراوحت قيم الوسط الحسابي بين أعلى قيمة حققتها الفقرة (r) التي تنشير إلى (التزام الكلية بالقوانين

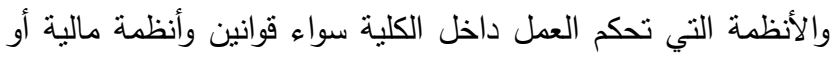

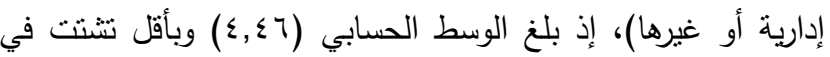


المجلة الدولية لضمان الجودة - المجلد الثاني - العدد الثاني، 9 ــr.

\section{ثالثاً: اختبار فرضيات البحث:}

تحليل علاقات الارتباط بين الحوكمة والأداء المتميز

يوضح الجدول (0) علاقات الارنباط بين الحوكمة والأداء المتميز ، إذ يتضمن وجود علاقة ارتباط إيجابية ذات دلالة معنوية عند مستوى معنوية (1., (•) بين الحوكمة والأداء المتميز التي بلغت (79,7, • ) وهي علاقة موجبة توضح قوة العلاقة بين المتغيرين، وهذا يدل على أنَّ تطبيق قواعد الحوكمة ينتج عنه زيادة أعلى في الأداء المتميز وبذلك قبول الفرضية الرئيسة الأولى والتي مفادها (توجد علاقة ارتباط معنوية ذات دلالة إحصائية بين الحوكمة والأداء المتميز

في الجامعات المبحوثة).

الجدول (ه): معاملات الارتباط بين متغيرات البحث.

\begin{tabular}{|c|c|c|}
\hline قيمة t الجدولية & $\begin{array}{c}\text { المتغير التابع } \\
\text { Y }\end{array}$ & المتغير المستقل \\
\hline 1,71 &., 00 & البعد الاقتصادي(X1) \\
\hline درجة ثقة & $\{, 0\}$ & قيمة t المحسوبة \\
\hline$\cdot, 9$. & ارتباط منوسط طردي & نوع العلاقة \\
\hline 1,71 & $\cdot$, TV & البعد الاجتماعي(X2) \\
\hline درجة الثقة & $7, \Upsilon \wedge$ & قيمة t المحسوبة \\
\hline$\cdot, 9$. & ارتباط جيد طردي & نوع العلاقة \\
\hline 1,71 &., 01 & البعد البيئي (X3) \\
\hline درجة الثقة & $\varepsilon, \cdot \wedge$ & قيمة t المحسوبة \\
\hline$\cdot, 9$. & ارتباط متوسط طردي & نوع العلاقة \\
\hline 1,71 & $\cdot, 79$ & الحوكمة (X) \\
\hline درجة الثقة & 7,07 & قيمة t المحسوبة \\
\hline$\cdot, 9$. & ارتباط جيد طردي & نوع العلاقة \\
\hline
\end{tabular}

المصدر : إدخال الييانات في البرنامج الإحصائي (SPSS).

أما على مستوى الفرضيات الفرعية المنبقة من الفرضية الرئيسة الأولى فقد كانت النتائج كما يأتي: هنالك علاقة ارتباط إيجابية طردية ذات دلالة معنوية عند مستوى معنوية (1 •, •) بين البعد الاقتصادي والأداء المتميز التي بلغت (00, •) وهي علاقة طردية معنوية موجبة توضح العلاقة بين المتغيرين مما يؤشر إلى التزام الكليات المبحوثة في وضع سياسات اقتصادية تساعدها في الحصول على التمويل وإدارة المخاطر مما ينعكس إيجابياً على تحقيق الأداء المتميز وبالتالي قبول الفرضية الفرعية الأولى التي مفادها (وجود علاقة ارتباط

ذات دلالة معنوية بين البعد الاقتصادي والأداء المتميز). هناك علاقة ارتباط إيجابية طردية ذات دلالة معنوية عند مستوى معنوية (1 (, • ) بين البعد الاجتماعي والأداء المتميز التي بلغت (TV) , · ) وهي علاقة موجبة توضح قوة العلاقة بين المتغيرين مما يؤثر نحو قيام الكليات المبحوثة بالتحديد الواضح للمسؤوليات والصلاحيات من ناحية فضلاً عن الهتمامها بالمسؤولية الاجتماعية من خلا حماية حقوق الأقلية وتحقيق التتمية الاقتصادية، مما ينعكس إيجابياً على تحقيق الأداء المتميز

\begin{tabular}{|c|c|c|c|}
\hline المئوية ا النسبة & المعياري & المتوسط & السؤال \\
\hline$\wedge ४, \wedge$ &., 79 & $\{, \Gamma \leqslant$ & 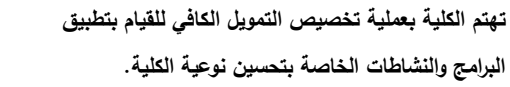 \\
\hline 14 & - & $\varepsilon, r$ & تالمزتز عمادة الكلية مفاهيم التعاون المشترك بين الموظفين على \\
\hline$\Lambda \leqslant$ & $\cdot, \vee \wedge$ & $\varepsilon, r$ & تحث عمادة الكلية ملاكها التدريسي والإداري على تقليم أفضل \\
\hline$\wedge \wedge, \varepsilon$ & $\cdot, \mathrm{Vr}$ & $\{, \leqslant r$ & 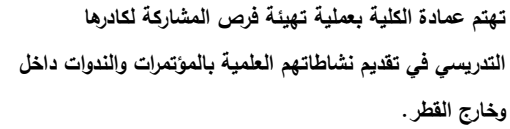 \\
\hline$\Lambda_{0, r}$ & זד, & צ צ & 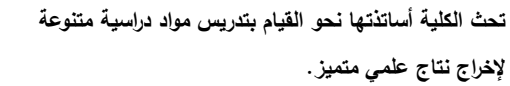 \\
\hline 14 & $\cdot, V \leq$ & $\varepsilon, r$ & تستوعب عمادة الكلية المشاكل التي توجه ملاكاتها العلمية \\
\hline$\Lambda Y, \Lambda$ & ד & $\{, 1 \leqslant$ & 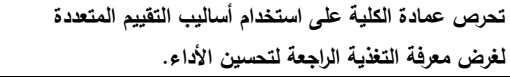 \\
\hline$\Lambda_{0, r}$ & .74 & \&,YY & 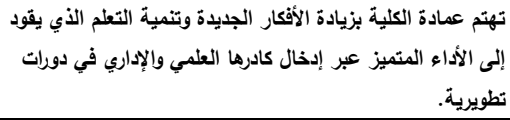 \\
\hline$\Lambda \varepsilon$ & $\cdot, \Delta V$ & $\varepsilon, r$ & توفى عمادة الكلية البيئة الملائمة لمدرِّيها وطلبتها للوصول \\
\hline$\Lambda \varepsilon$ & $\cdot, V 4$ & $\varepsilon, Y$ & التعمل الكلية على القيام بإجراء تدوير بين أعضاء الكادر . \\
\hline$\Lambda_{0, r}$ & $\cdot, V Y$ & \&,YY & 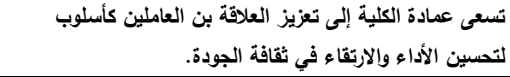 \\
\hline$\Lambda \leqslant, \varepsilon$ & •, & $\varepsilon, Y r$ & الأفكار والمقترحات الجديدة الداعمة للتعلم والنمو بكادرية التدريسي وتقدم التشجيع نحو طرح \\
\hline$\Lambda_{0, \tau}$ & $\cdot, v_{1}$ & $\varepsilon, Y \wedge$ & المجموع \\
\hline
\end{tabular}

يوضح الجدول (ع) قيم الأوساط الحسابية والانحرافات المعيارية والنسبة المئوية لإجابات عينة البحث للمتغير الرئيس الأداء المتميز (Y)

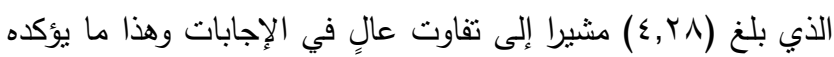

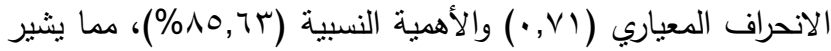
إلى اهتمام الكليات الأهلية المبحوثة بالجهود الأهيلة الفربية للأفراد العاملين

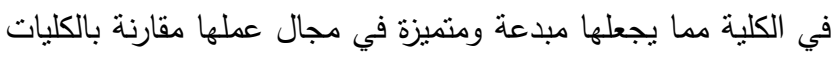
الأخرى. أما على مستوى الفقرات، إذ تم قياس هذا المتغير بالفقرات (1-9 (1) فقد تراوحت قيم الوسط الحسابي بين أعلى قيمة حققتها الفقرة

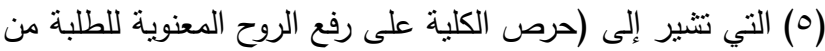

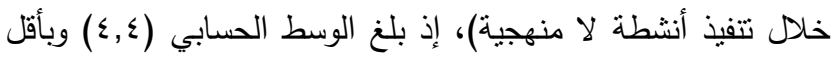

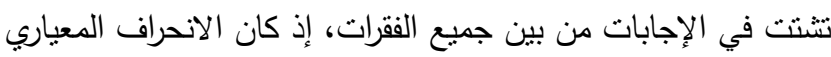

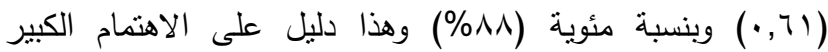
للكليات المبحوثة بتعزيز ورفع الروح المعنوية لطلبتها عبر تتفيذها

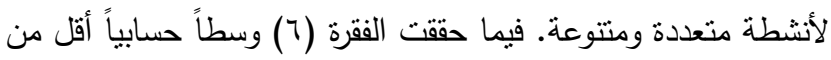
وسط المقياس بقيمة (ץ.,_؟) وكأقل وسط حسابي بانحراف معياري (10, •) وبنسبة مئوية (ع, •^\%\%) والتي تشير إلى (قيام عمادة الكلية بمنح المكافأة للأساتذة والقادة الإداريين لما يحققونه من مستويات

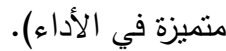


الرئيسة الثانية والتي تتص على أن هناك تأثيراً ذا دلالة معنوية

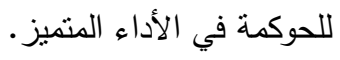

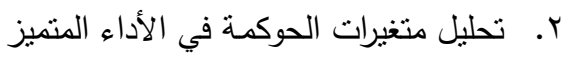

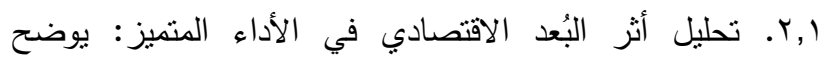

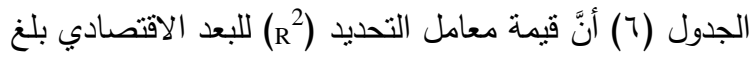

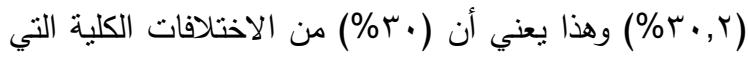

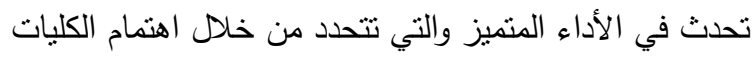
المبحوثة في تطبيق السياسات الاقتصادية التي تتبعها، وأنَّ نسبة (•r\%) المتنقية تمثل نسبة إسهام المتغيرات غير الداخلة

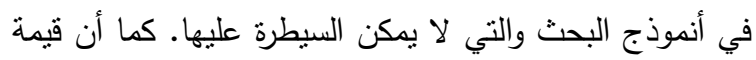

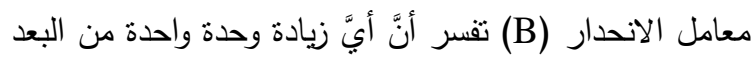

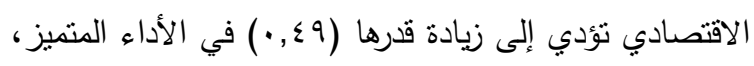

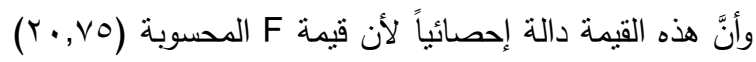

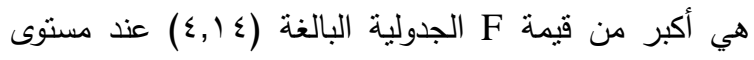

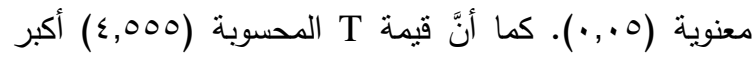

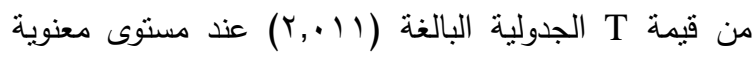

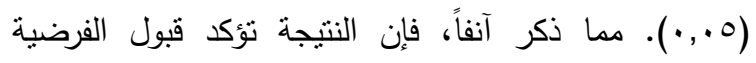

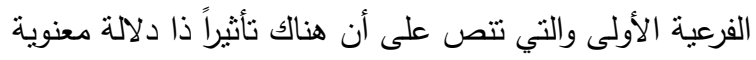

$$
\text { للبعد الاقتصادي في الأداء المتميز. }
$$

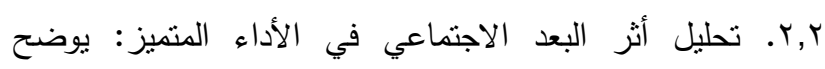

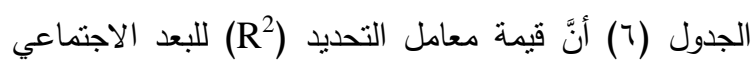

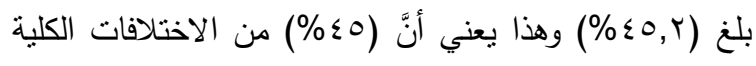

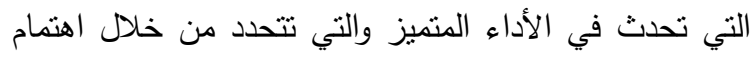

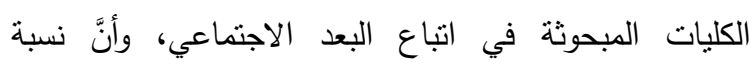
(\%00) المنبقية تمثل نسبة إسهام المتغيرات غير الداخلة في

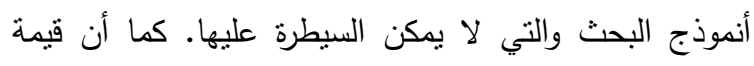

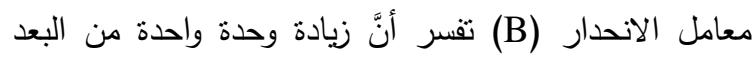

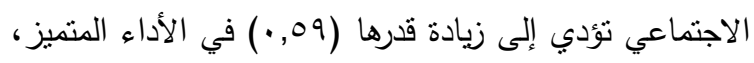

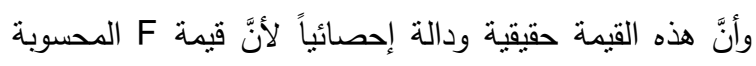

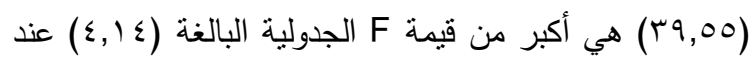

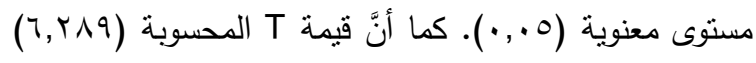

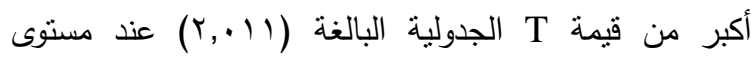

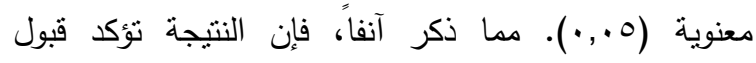

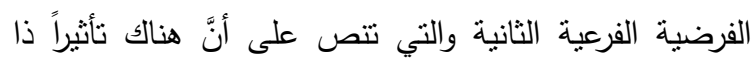
دلالة معنوية للبعد الاجتماعي في الأداء المتميز.

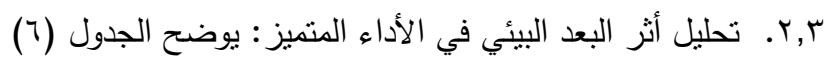

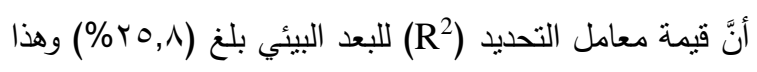

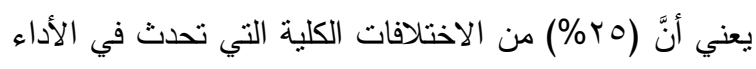

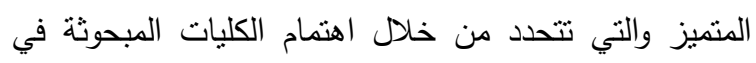

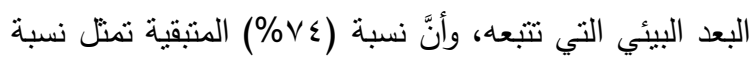

وبالتالي قبول الفرضية الفرعية الثانية التي مفادها( وجود علاقة ارتباط ذات دلالة معنوية بين البعد الاجتماعي والأداء المتميز ) .

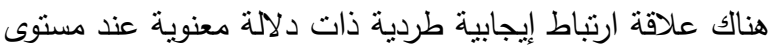

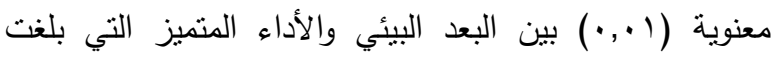

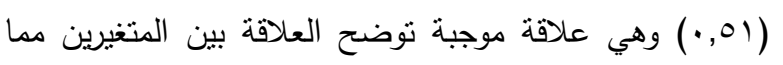

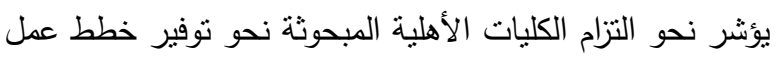

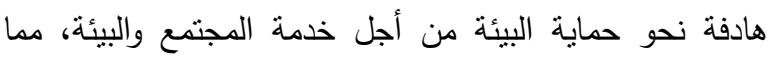

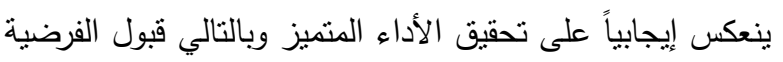

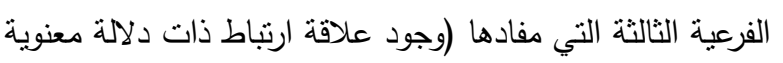

$$
\text { بين البعد البيئي والأداء المتميز). }
$$

\section{تحليل تأثير متفيرات الحوكمة في الأداء المتميز.}

تتضمن هذه الفقرة تحليل علاقة تأثير المتغير المستقل فئل الكيز (الحوكمة) في المتغير التابع (الأداء المتميز)، ويتم فياس تأثنير الحوكمة ومتغيراتها الفرعية في الأداء المتميز وذللك باستخدام (معامل تحليل الانحدار البسيط) للتحقق من قبول الفرضية الرئيسة الثانية

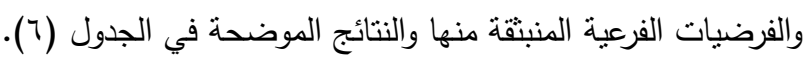

\begin{tabular}{|c|c|c|c|c|c|c|c|}
\hline انعليدة & 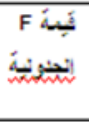 & أنحسبورية Fل & 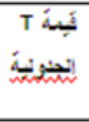 & التحسبرةبة & الحخذز B & أشخدند & انسنسنَّرِ \\
\hline مغورية & 4.14 & 20.75 & 2.011 & 4.555 & 0.49 & $\% 30.2$ & الإنشايذي \\
\hline مشورية & 4.14 & 39.55 & 2.011 & 6.289 & 0.59 & $\% 45.2$ & 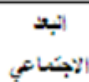 \\
\hline بنورية & 4.14 & ${ }^{\circ} 16.66$ & 2.011 & ${ }^{6} 4.081$ & 0.23 & $\% 25.8$ & انبئ \\
\hline مشورية & 4.14 & 451.03 & 2.011 & 67.143 & 0.65 & $\% 51.5$ & 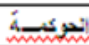 \\
\hline
\end{tabular}
الجدول (؟) تحليل متغيرات الحوكمة في الأداء المتميز.

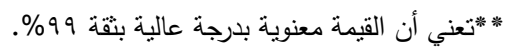
\%تعني أن القيمة معنوية بثقة 90\%.

يثير الجدول (آ) إلى النتائج الآتية:

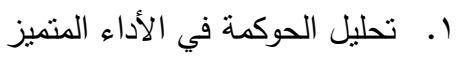

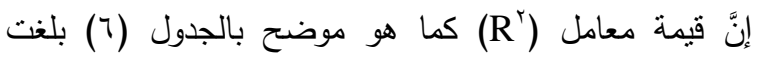

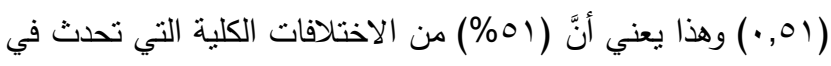

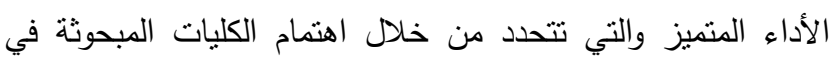
الأداء المتميز ، وأن نسبة (9 و \%) المنتقية تمثل نسبة إسهام المتغيرات

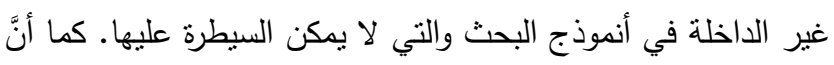

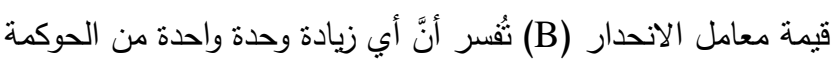

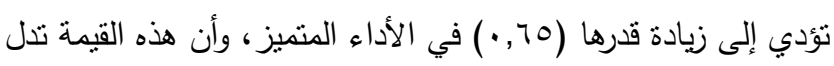

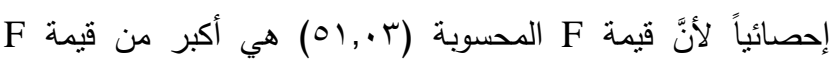

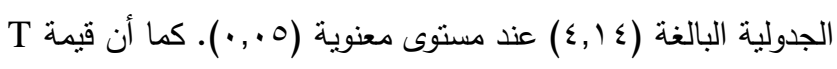

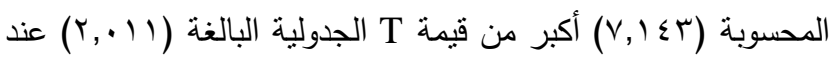

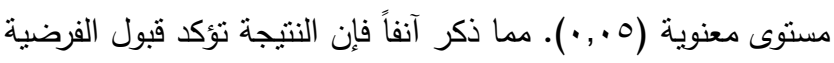


يعزز من نقافة كل من (التدريسين، والطلبة، والموظفين)

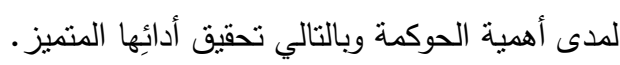

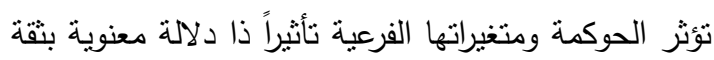
90\% في الأداء المتميز ، مما ينعكس على قيام الكليات العراقية الأهلية بتركيز اهتمامها على إجراءات الحوكمة الحاء

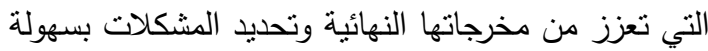
وبالتالي تحقق لها التميز في أدائها . وجود تفاوت عالٍ في الإجابات الخاصة بفقرة الأداء المتميز

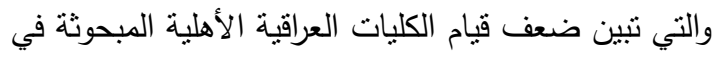
تقديم المكافأة للأساتذة وللمديرين لما يحققونه من إنجازات

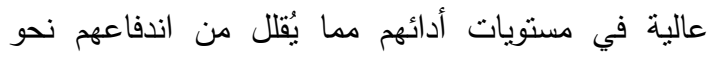
العمل والتعلم والنمو في الكلية.

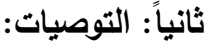

استتاداً إلى ما توصل إليه البحث من الاستنتاجات، يقدم

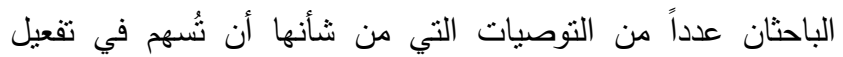

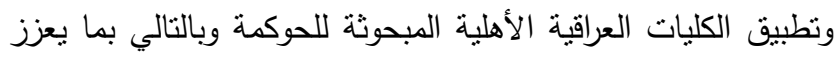
تحقيق الأداء المتميز ، ويمكن إجمال هذه التوصيات بما يأني: تتمية إدراك إدارة الجامعات بأهمية الحوكمة نظراً لما تمثله من قوانين ونظم تهدف نحو تحقيق الجودة والتميز في

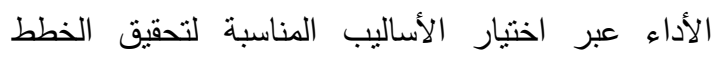
الفاعلة لأهدافها. ضرورة قيام الكليات العراقية الأهلية المبحوثة بتوفير النظم المحاسبية الفاعلة التي تحسن اتخاذ القرار الإداري وذللك التهات

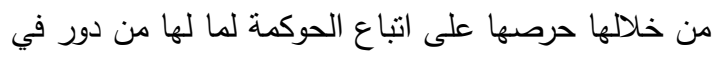

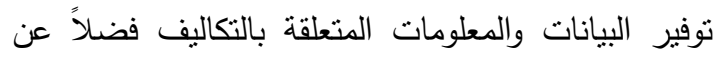
المعلومات المتعلقة بأدائها مع إمكانية الحصول عليها بطريقة ميسرة من قبل جميع الأطراف . ضرورة قيام الجامعات العراقية بعقد ندوات وورش العمل لئل

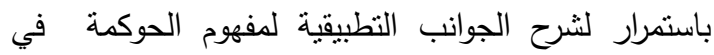
البيئة الاقتصادية، فضلاً عن تأسيس جمعيات مهنية تهتم بمجال الحوكمة وتفعيل دورها بما يعزز من منع حدوث الفشل المالي وتعزيز الإصلاح الاقتصادي في بيئتها التعليمية . ينبغي أن تحرص الجامعات العراقية على احتواء مواردها البشرية كافة المتمثلة ب(الكوادر التدريسية، والطلبة،

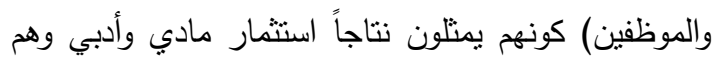

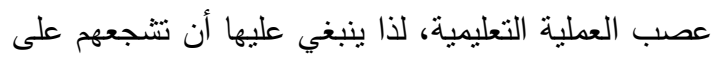

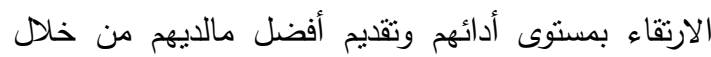
منحهم المكافأة لضمان استمرارية التميز في أدائهُم.
إسهام المتغيرات غير الداخلة في أنموذج البحث والتي لا يمكن

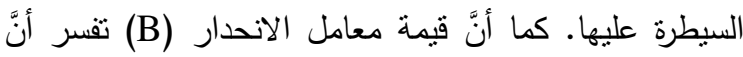
زيادة وحدة واحدة من البعد البيئي تؤدي إلى زيادة قدرها

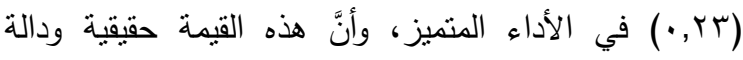

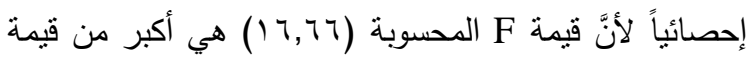

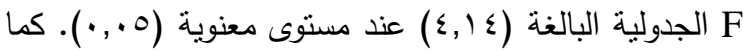

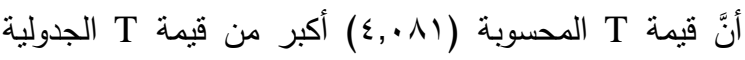

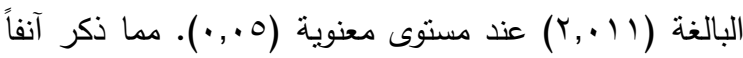

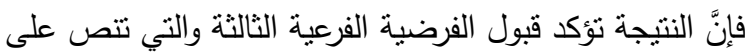
أنَّ هناك تأثثراً ذا دلالة معنوية للبعد البيئي في الأداء المتنميز.

\section{المبحث الرابع: الاستتناجات والتوصيات

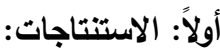

في هذا المبحث الحالي تم التوصل إلى مجموعة من المن الاستتناجات كان من أبرزها ما يأني:

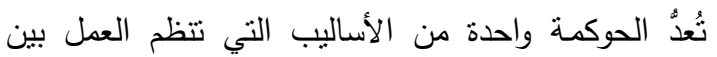
الأقسام والوحدات من (التدريسيين، والطلبة، والموظفين)

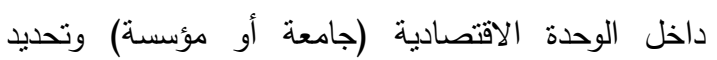
أساليب التواصل والرقابة فيما بينها وتنظيم سبر العلاقات

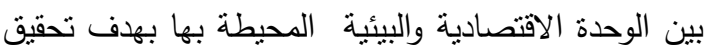

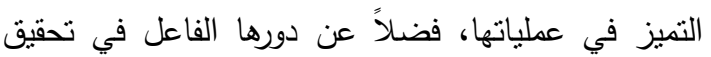

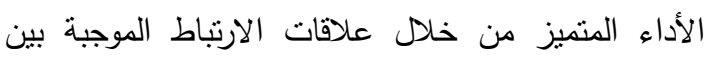

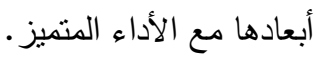
أنثارت النتائج أنَّ البعد البيئي قد حقق أدنى علاقة ارتباط إيجابية متوسطة مع الأداء المتميز التي بلغت (10,.•)،

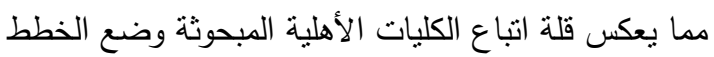
الني تعمل على مواجهة تهديدات البيئة. بينت النتائج أنَّ البعد الاجتماعي قدا حقق أعلى على علاقة ارتباط طردية جيدة مع الأداء المتميز التي بلغت (Vآ, •)،

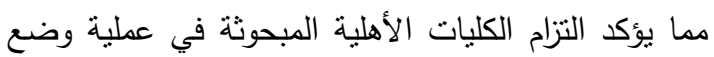
القوانين والأنظمة التي تحكم طبيعة العمل في داخلها،

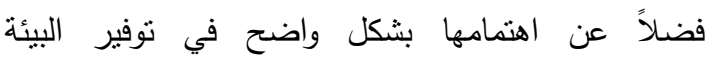
الاجتماعية والقانونية التي تتصف بكل مقومات الصدق

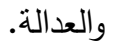

حصل البعد الاقتصادي، هو البُعد الأول من متغير

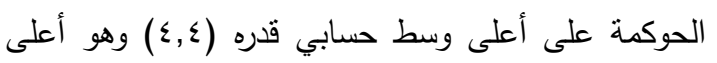
من الوسط الفرضي، مما يؤكد اهتمام الكليات العراقية الأهلية المبحوثة في عملية وضع السياسات الاقتصادية وتوفير المعلومات المالية وغير المالية مما يمكنها من المناع التحديد المستمر لمصادر الخطر وتقويمها باستمرار مما 
College of Business and Economics, Baghdad University, 2012.

10. Al-Mashhadani, Bushra Najm Abdullah and Al-Fatlawi, Laila Naji Majeed, "The Approaches in Measuring the Management of Corporate Profits and the Impact of Governance on Reduction," Journal of Administration and Economics, No. (93), University of Baghdad, 2012.

11. Al-Qaryouti, Mohammad Al-Qasem, "Organizational Behavior: A Study of Individual and Collective Human Behavior in Business Organizations", 6th Edition, Dar Al-Wa'el for Publishing and Distribution, Amman, 2012.

12. Al-Rikabi, Ali Khalaf Salman, AlMashhadani and Omar Iqbal Tawfiq, "Corporate Governance and its Role in Reducing the Problems of Agency Theory, Ninth International Conference (Arab Economic Situation and Future Options), 2011.

13. Al-Rubaie, Sumaya Abbas Majeed, "Knowledge Industry and Functional Alienation and its Impact on Outstanding Performance", An Exploratory Study in the Faculties of Mustansiriya University, Unpublished Ph.D. Dissertation in Business Philosophy, 2015.

14. Al-Ruwaishdi, Hossam Ali Muheibis, "Adoption of International Quality Awards Standards in Achieving Outstanding Performance - An Exploratory Study of a Sample of Deans and Heads of Scientific Departments at Baghdad University", Master Thesis, College of Business and Economics, University of Baghdad, 2009.

15. Al-Shammari, Hassanein Ragheb Taleb, "A Proposed Model for the Role of Management Accountant in Implementing Corporate Governance Mechanisms: A Field Study in a Sample of Iraqi Mixed Industrial Companies", Master Thesis in Accounting, University of Baghdad, College of Administration and Economics, 2010.

16. Bani Hamdan, Khalid Mohammed Talal and Idris, Wael Mohammed, "Strategy and Strategic Planning", Dar Al-Masirah for Publishing and Distribution, Amman, 2007.

17. Bashiwa, Hassan Abdullah and Al-Barwari, Nizar Abdul Majeed and Eshouni, Mohammed Ahmed, "Institutional Excellence Introduction to Quality and Best Practices Principles and Applications", First Edition, Al-Warraq for Publishing and Distribution, Amman, 2013.

\section{References:}

1. Abdul-Hakim, Hisham Talaat and Dalloul, Emad Abdul-Hussein, "Corporate Governance and its Role in Fair Valuation of Ordinary Shares: An Empirical Study in the Iraq Stock Exchange", Journal of Administration and Economics, No. 77, Mustansiriya University, 2009.

2. Abul-Ata, Nermin, "Corporate Governance for Progress with a Spotlight on the Egyptian Experience", Journal of Economic Reform, No. 8, 2003.

3. Al-Ali, Abdul Sattar and Qandilji, Amer Ibrahim and Omari, Ghassan, "Introduction to Knowledge Management", the first edition, Dar Al-Masirah for Publishing and Distribution, Amman, 2006.

4. Al-Amiri and Al-Ghalbi, Saleh Mahdi, Taher Mohsen, "Administration and Business", Wael Publishing and Distribution House, Amman, Jordan, 2008.

5. Al-Amyan, Mahmoud Salman, "Organizational Behavior in Business Organizations", 6th edition, Wael Publishing \& Distribution House, Amman, 2013.

6. Al-Arini, Manal, "The Reality of Applying Governance from the Viewpoint of the Members of the Administrative and Academic Bodies Working at Imam Muhammad bin Saud Islamic University", International Journal of Specialized Education, Vol. 3, No. (12), 2015.

7. Al-Azzawi, Fares Salah Najm, "Requirements for Establishing International Manufacturing Specifications and their Impact on Achieving Some Dimensions of Outstanding Performance - a Study from the Viewpoint of a Sample of Workers in the General Company for the Manufacture of Pharmaceuticals and Medical Supplies / Nineveh", Master Thesis in Industrial Management, Faculty of Management and Economics. University of Mosul, 2010.

8. Al-Mahameed, Saud Mohammad, "The Relationship between Knowledge Sharing and Individual Adaptability: a Field Study in the Industrial Companies Listed in the Amman Stock Exchange", The Jordanian Journal of Business Administration, University of Jordan, Journal (7), Issue (2), 2011.

9. Al-Mashhadani, Amna Abdul-Karim, "Human Capital and Promoting the Culture of Performance Excellence and their Impact on Organizational Status- Exploratory Research in the Ministry of Oil Center", Master Thesis in Business Administration, 
Instructions / Case Study of Omani Public Shareholding Companies", Damascus University Journal for Economic and Legal Sciences, Volume (24), First Issue, Faculty of Economics, 2008.

26. Rowland's, J., "A cadmic Governance" in the Contemporary University", Perspectives from Anglophone Nations, School of Education, Beak in University, Warrnambool Australia, eBook , 2017.

27. Schiffman L and kanuk L ,"Consumer Behavior",7th ,new jersey ,prontice -hall, 2000.

28. Stankosky ,D. Sc. ,Michael ,"creating the Discipline of Knowledge Management ",the Latest in university Research ,U.S.A. ,Elsevier Butter worth Heinemann, , 2005.

29. Wheelen, Thomas \& Hunger, David, "Strategic Management and Business Policy, 7th ed, Prentice-Hall International Inc, U.S.A ,2000.

30. Youssef, Mohamed Hassan, "Determinants of Governance and its Standards with Special Reference to the Application Pattern in Egypt”, Egyptian Investment Bank, 2007.

31. Zairi and Emark, Mohamed, John, "Best Practices of Excellence", translated by Mohammad Jamaluddin Noir and Emark John, Comprehensive Electronic College Publishing House, 2005.
18. Drucker ,peter.F , "The Discipline of Innovation" ,Harvard Business Review ,Nov. No.9 ,P.152-1553, 2010.

19. Harhouche, Salem, Adel, Moayad Saeed, "Human Resources Management", Baghdad, 2010.

20. Hassan, Salah, "Banks, Banks and Business Organizations: Standards of Governance of Financial Institutions", 1st ed., Dar El Ketab El Hadith, Cairo, 2011.

21. Kamble ,Raju R,"Management Skills for Organizational Performance : Analytical study" ,Indian streams Research Journal ,vol.1 ,Issue.1 ,PP.23-27, 2011.

22. Kezar A. J., ans Eckel PD, "Meeting Todays Governance Challenges: A Synthesis of the Literature and Examination of Future Agenda for Scholarship. The Journal of Higher Education, Vol (76), No (4), 2009.

23. Khawam, Habib Sameeh, "Job Satisfaction of Employees and its Effects on Performance", An Empirical Study on Al-Jazeera Satellite Network, Unpublished Master Thesis at the Arab British Academy for Higher Education, 2006.

24. Najjar, Ahmad Munir, "The Banking Dimension in Corporate Governance", Union of Kuwaiti Banks, No. (40), 2007.

25. Rihawi, Maha Mahmoud Ramzi, "Joint Stock Companies Between Governance, Laws and 